\title{
Incumbent repositioning with decision biases
}

\section{Xianjin Du${ }^{1}$ । Meng $\mathrm{Li}^{2}$ (i) । Brian $\mathrm{Wu}^{3}$}

${ }^{1}$ School of Management, Hefei University of Technology, Hefei, China

${ }^{2}$ School of Business, Rutgers University, Camden, New Jersey

${ }^{3}$ Ross School of Business, University of Michigan, Ann Arbor, Michigan

\section{Correspondence}

Meng Li, School of Business, Rutgers

University, Camden, NJ.

Email: meng.li@rutgers.edu

\section{Funding information}

National Natural Science Foundation of China, Grant/Award Numbers: 71871076, 71690235, 71521001

\begin{abstract}
Research Summary: Incumbent firms often reposition themselves in response to entrants, but when doing so they incur repositioning costs. Incumbent repositioning costs and the associated decision biases have been identified in the economics, operations, and strategy literatures as critical aspects of the competitive interactions between incumbents and entrants, but they have received limited attention in game-theoretic treatments at the strategy level. To fill this gap, we develop a strategic mental model to analytically characterize the impacts of repositioning costs and decision biases on firms' equilibrium strategies and profits. Including these costs and biases changes, the nature of strategic dynamics as well as introduces new implications for strategic choice.
\end{abstract}

Managerial Summary: Our analysis shows that although biases by themselves are unequivocally harmful for firms, both the entrant and incumbent can earn more when they are biased than when neither one is. In particular, when an entrant is biased in estimating an incumbent's repositioning ability, this unequivocally reduces its own performance, if the incumbent is aware of the entrant's bias and has correctly assessed it. In a similar vein, when an incumbent is biased in its estimation of the entrant, this hurts the incumbent. However, both the entrant and the incumbent can earn more than they would in a setting where both firms are unbiased. Furthermore, the incumbent is not necessarily better off by being less biased-that is, aware of but with an inaccurate assessment of entrant bias. 


\section{K E Y W O R D S}

behavioral strategy, flexibility, managerial behavior, overconfidence, repositioning costs

\section{1 | INTRODUCTION}

Entrants have been identified as one important determinant of the market dynamic, especially the profitability of incumbents (McCann \& Vroom, 2010; Ravi Kumar \& Sudharshan, 1988; Simon, 2005). Incumbents can be affected, for instance, when entrants attempt to penetrate a market by reducing prices, which intensifies competition among firms (Besanko, Dranove, Shanley, \& Schaefer, 2009; McCann \& Vroom, 2010; Rumelt \& Teece, 1994; Simon, 2005). In response, to avoid a confrontation that could lead to a destructive price war, incumbent firms often reposition their products or brands (Carpenter, 1989; Ellickson, Misra, \& Nair, 2012; Hauser \& Shugan, 2008; Trout \& Ries, 1982). One well-known example of repositioning is Johnson \& Johnson's Tylenol brand of analgesics. Tylenol once dominated the over-the-counter market for pain relief by establishing the drug as effective with few side effects. After a competitor, Advil, entered the market in 1984, Tylenol revised its marketing to emphasize Tylenol's gentleness (Hauser \& Shugan, 2008). Another example is U.S. local retailers' decision to shift their pricing formats after Walmart entered the market in the 1990s (Ellickson et al., 2012).

While repositioning can be advantageous, it may come at a cost because past strategic decisions, which often entail prior commitments (Ghemawat, 1991), may need to be changed. Typical costs associated with repositioning ("repositioning costs") include investments to overcome within-firm managerial resistance to change, to rework channel relationships, and to educate (or advertise to) consumers about the new positioning (Menon \& Dennis, 2017). These repositioning costs have substantial implications for the competitive interplay between firms (Ellickson et al., 2012; Wang \& Shaver, 2014, 2016). Consider the case of Mobileye (Yoffie, 2014), a technology leader in vision technologies for advanced driver assistance systems (ADAS), which was highlighted in Menon and Dennis (2017, p. 1954):

Rather than selling its technologies directly to original equipment manufacturers (OEMs), Mobileye initially partnered with Tier 1 automotive suppliers such as TRW and Autoliv who, in turn, sold the OEMs integrated ADAS using Mobileye and nonMobileye vision technologies. Mobileye subsequently instituted an exclusivity policy under which it would only work with Tier 1 suppliers who were not developing (or were no longer developing) non-Mobileye ADAS. While this policy change resulted in the loss of some partners (e.g., Autoliv), it led the remaining partners (e.g., TRW) to emphasize the development of complementary parts (i.e., non-camera technology) for a Mobileye-centered ADAS system while deemphasizing development of substitutes for Mobileye's vision technology. The success of automotive vision technologies depends on the technology's ability to accurately identify objects under varied driving conditions and accurate identification requires an object identification database that improves with extensive in-field use of the technology. Over time, then, the cost to a Mobileye current partner of repositioning itself to be a direct competitor of Mobileye is increasing, and, hence, Mobileye's policy change arguably benefits Mobileye by reducing the field of potential vision-technology competitors despite exploding ADAS demand. 
Although repositioning costs play an important role in competitive interactions, entrants are often unable to precisely assess the incumbent's repositioning costs due to the prevalence of decision biases, systematic errors in how executives process information in strategic decision making (Horn, Lovallo, \& Viguerie, 2005; Menon, 2018; Menon \& Dennis, 2018; Schwenk, 1984). These decision biases prevent managers from completely avoiding errors in estimating a competitor's ability (Goldfarb \& Yang, 2009; Li, Petruzzi, \& Zhang, 2016; Li, 2019; Prescott \& Visscher, 1977). For example, using controlled laboratory studies, Moore and Cain (2007) and Cain, Moore, and Haran (2015) find that entrants to a market tend to systematically overestimate or underestimate their rivals. In a similar vein, using the data from U.S. local telephone markets shortly after the Telecommunications Act of 1996, Goldfarb and Xiao (2011) demonstrate that a new entrant's ability to predict the incumbent's behavior varies and depends on the manager experience and education of the new entrant. A similar bias exists for diversifying entrants as well as de novo ones. To illustrate, in the early 1990s, when Anheuser-Busch diversified to enter the snack food business, the beer giant greatly overestimated the repositioning costs of the incumbent, Frito-Lay, which repositioned itself efficiently (Horn et al., 2005; Stalk Jr. \& Lachenauer, 2004).

Against this backdrop, this paper explores how firms' decision biases affect their performance outcomes, with entry/repositioning as the specific strategic context. While there is a rich tradition that recognizes the fundamental importance of decision biases in decision-making (Csaszar \& Levinthal, 2016; Gavetti, 2012; Kaplan, 2011; Levinthal, 2011; Porac, Thomas, \& Baden-Fuller, 1989; Zajac \& Bazerman, 1991; Zhang, Gou, Liang, \& Huang, 2013), this tradition has primarily taken a firmcentric perspective and paid relatively less attention to the impact of decision biases on competitive interactions. The strategic mental model approach is an attempt to address this gap by incorporating the role of cognition into game-theoretic analyses (Menon, 2018). Thus, we develop our strategic mental model within the incumbent repositioning context, focusing on three key components: parameter specification, parameter assessment, and belief system, as discussed below.

First, the specification of the key strategic parameter-incumbent repositioning costs—builds on the pioneering work of Ghemawat (1991) on a firm's commitment to making irreversible capacity decisions, but extends it to the positioning context with differentiated firms. In particular, the incumbent (she) is the market leader and initially a monopoly with the best possible market position. After the arrival of the entrant (he), the incumbent can adjust her position in order to differentiate herself from him. The repositioning costs of this adjustment depend on the incumbent's ability to change her activities, which we term "repositioning ability." When a firm has a high repositioning ability, repositioning costs will be lower for a given degree of repositioning. This ability may, for instance, be related to a firm's possession of advanced machinery or technologies that facilitate the reconfiguration of its business processes (Eisenhardt \& Martin, 2000; Helfat \& Martin, 2015). The repositioning ability of an incumbent may be low for a variety of reasons such as existing commitments. Examples here include Apple's iPhone's commitment to using its own operating system and distribution channel (Ghemawat, 1991; Hill \& Rothaermel, 2003; Pacheco-De-Almeida, Henderson, \& Cool, 2008), a newspaper business's inability to reposition when Craigslist enters the local market (Seamans \& Zhu, 2017), and Loblaw Companies Limited, a major grocery chain in Canada, that built superstores before Walmart entered the market, and that could not efficiently switch to a small-store format (Besanko et al., 2009).

Second, the strategic mental model emphasizes the need to study firms' ability to accurately assess the value of strategic parameters. This emphasis is important because the assumption of classical game-theoretical models that actors in the system have an accurate assessment of various relevant parameters is often violated by real-world firms (Kaplan, 2011; Levinthal, 2011; Menon, 2018; Simon, 1976). This means that, in our context, a new entrant, as the competitor of the incumbent, 
needs to assess the value of the incumbent's repositioning costs, and this assessment may be inaccurate. Thus, we use the term "underestimation bias" ("overestimation bias") when the entrant underestimates (overestimates) the incumbent's repositioning ability.

Third, to incorporate decision bias into a game-theoretic analysis, one also needs to characterize firms' belief systems (Aumann \& Brandenburger, 1995). In practice, incumbents may not know the entrant is biased and may also inaccurately assess the entrant's decisions. For example, as an incumbent motorcycle manufacturer, Harley Davidson inaccurately assessed Honda's entry into the U.S. lightweight motorcycle segment during the early 1960s (Menon, 2018; Pascale \& Christiansen, 1989). In our context, an inaccurate assessment can mean that the incumbent is either unaware of entrant bias or has an awareness of entrant bias, but inaccurately perceives the level of bias. Although the entrant is biased on some level, the incumbent behaves as though the entrant were unbiased or differently biased.

The development of these three key components-repositioning costs, the entrant's assessment of repositioning costs, and the incumbent's belief system regarding the entrant-in turn sheds insights on each of these components. For repositioning costs, we illustrate their influence on the competitive interactions between incumbents and entrants by building on Ghemawat (1991) to develop a baseline model in which both firms are unbiased. If entrant position is exogenous, that is, the entrant position is not strategically determined by the entrant, the incumbent's profit always increases when she possesses a superior repositioning ability, because it allows her to efficiently differentiate herself from the entrant. When the entrant position is endogenous, that is, the entrant can strategically decide his position, the incumbent's superior repositioning ability also reduces the need for the entrant to differentiate, thus increasing competitive pressure on the incumbent and potentially reducing incumbent profit. These different outcomes result in two implications. First, the entrant's equilibrium profit can increase rather than decrease in relation to the incumbent's repositioning ability. Second, the incumbent faces less competition when her repositioning ability is lower. As a result, the incumbent's relative advantage, defined as the incumbent's relative performance over the entrant (Alcácer, Dezsö, \& Zhao, 2015; Barney, 1991; Chatain \& Zemsky, 2007; Pacheco-de Almeida \& Zemsky, 2007), prevails, especially when the incumbent's repositioning ability is relatively low.

For the entrant's assessment on repositioning costs, we find that, consistent with intuition, both underestimation bias and overestimation bias lead to suboptimal positioning decisions, inevitably decreasing the entrant's performance. We find, however, that entrant bias can either increase or decrease the incumbent's performance, depending on the type of bias. In particular, the entrant's underestimation bias helps the incumbent, whereas his overestimation bias hurts the incumbent.

For the incumbent's belief system regarding the entrant, we first consider a setting where the incumbent does not accurately assess entrant bias despite having an awareness of it, that is, the incumbent anticipates a level of entrant bias that differs from his actual bias. In this setting, we find that, although incumbent bias always results in self-harm, it can boost the incumbent's performance relative to that of the entrant. To clarify, incumbent bias can be a drag on both the incumbent and the entrant; however, the drag for the entrant can be greater than the incumbent's losses due to her decision bias, enhancing her relative advantage. Perhaps more interestingly, in this setting where neither the incumbent nor the entrant has an accurate assessment of the other, both firms can actually earn more than in the baseline model where both firms are unbiased, depending on the values of repositioning costs and decision biases. This means that, although the incumbent's and entrant's respective biases always result in harm to the individual firm, firms can be better off when they both behave in a biased rather than an unbiased way. We further consider a setting in which the incumbent is completely unaware of the entrant's decision bias, rendering her even more biased. Interestingly, this increased bias does not necessarily inflict further self-harm on the incumbent. In fact, the 
incumbent's complete lack of awareness can simultaneously benefit both the incumbent and the entrant, leading to better performances for each firm compared with when the incumbent is aware of entrant bias (but has an inaccurate assessment), depending on the magnitude of the entrant's and incumbent's respective biases.

\section{2 | LITERATURE AND CONTRIBUTIONS}

Although repositioning costs is a key aspect of strategy practice, the formal modeling of repositioning costs in strategy has only recently begun with Menon and Dennis (2017). Their "starting point is Pankaj Ghemawat's (1991) theory of commitment as the essential element in identifying strategic choices. Ghemawat persuasively argues that a strategic choice is one that involves commitment and that committed choice creates the persistent pattern of action typically characterized as strategy" (Menon \& Dennis, 2017, p. 1954). Following this argument, Menon and Dennis (2017) analytically investigate the interaction between an incumbent (innovator) and an entrant (follower). Within their setting, the incumbent develops and introduces a new product generation and then chooses to offer either generous or stingy licensing terms to a follower who can imitate the innovation or become a "complementor." The follower's choices are modeled as involving possible repositioning costs because the activity systems supporting imitation versus complementarity are different. We add to this pioneering research by investigating the post-entry repositioning of the incumbent, one prevalent strategy in practice. We find that the entrant's equilibrium profit can increase rather than decrease in relation to the incumbent's repositioning ability, while the incumbent's relative advantage prevails if her repositioning ability is relatively low.

More importantly, we focus on settings where the entrant and the incumbent are not necessarily rational, thus contributing to the general realm of behavioral strategy (Cyert \& March, 1963; Eggers \& Kaplan, 2013; Gavetti, 2012; Helfat \& Peteraf, 2015; Kaplan, 2011; Levinthal, 2011; Miller \& Chen, 1994). While this literature is rich, it has paid little attention to the impact of decision biases on competitive interactions. Consequently, the literature calls for more research to incorporate decision biases into game-theoretic analyses (Menon, 2018). We follow this perspective to investigate the theoretical impact of decision biases in a strategic entry/repositioning context. When firms' biases are considered, this leads to counterintuitive results on firms' performance; although the prior behavioral strategy research often documents that decision biases harm firm performance, they can potentially be a positive force under certain conditions.

This paper also contributes to the literature on incumbent strategies in response to entrants entering the market. These responses are among a firm's most important strategic decisions and have long been a central issue in economics, strategy, marketing, and operations (Dixit, 1979; Economides, 1984; Hauser \& Shugan, 2008; McCann \& Vroom, 2010; Modigliani, 1958). Recent studies have focused on one post-entry defense strategy available to incumbents-repositioning — and conclude that repositioning costs are fundamental to the strategic interactions of firms' activity systems (Ellickson et al., 2012). To model repositioning costs, we follow the tradition of Hotelling (1929) and numerous other works he inspired (e.g., Alcácer et al., 2015; Dixit \& Stiglitz, 1977 and Thomas \& Weigelt, 2000). In Hotelling's model without repositioning costs, each firm's equilibrium strategy is to locate at the ends of the market, maximally differentiating itself from its competitor (d'Aspremont, Jaskold Gabszewicz, \& Thisse, 1979). Most real-world examples, however, reveal a strategy that is more consistent with our theoretical prediction that firms are not necessarily located at the two ends of the Hotelling line. Accordingly, this paper offers insights that help reconcile the gap between theory and practice. 
Also relevant to our work here is the literature on leader or follower relative performance, which forms the basis of the definition of relative advantage, a major area of research in strategic management (Barney, 1991; Hawk, Pacheco-De-Almeida, \& Yeung, 2013; Lieberman \& Montgomery, 1988, 1998). We enrich this literature by incorporating repositioning costs and decision biases into a classical model with differentiation and market entry. By doing so, we offer three observations. First, the incumbent can gain more profit than the entrant when her repositioning ability is relatively low rather than high. While the incumbent's repositioning ability benefits herself, it may also benefit the entrant by the same or an even greater amount. Second, although the entrant's estimation bias always hurts the entrant, this bias can enhance his advantage (as a follower) relative to the incumbent. Third, the incumbent's relative advantage is not necessarily lower than that of the entrant when she is biased rather than unbiased in perceiving the entrant's actions. The incumbent's lack of awareness as a decision bias can actually contribute to her own relative advantage.

\section{I STRATEGIC MENTAL MODEL}

In this section, we present our strategic mental model in the context of entry/repositioning. The model is based on the standard Hotelling formulation (d'Aspremont et al., 1979; Hotelling, 1929). In particular, we consider a market where the ideal points of consumers are distributed uniformly in $[-0.5,0.5]$, and consumers with ideal point $t \in[-0.5,0.5]$ value a firm of position $x: R-(x-t)^{2}$. Here, the firm's position $x$ can be either geographic, as in a store's or a restaurant's physical location, or a space of preferences, as in the sweetness of a soft drink. $R$ is the consumers' reservation price, which is assumed to be the same for all consumers, and high enough so that all consumers buy from the firm. Next, $(x-t)^{2}$ is the disutility incurred by consumers if they are geographically distant from the firm or their ideal product does not match the product the firm is offering. The above framework or similar ones have been widely adopted in the literature of position/price competition (Tabuchi \& Thisse, 1995; Tyagi, 2000).

We follow this literature to allow firms to position themselves anywhere on the real line, meaning firms can, for example, set up their location anywhere along a street, although consumers are only located around the geographic center of the street. If one forces firms' positioning space $[-0.5,0.5]$ to the interval in which consumer preferences lie (see Section 7), then identical firms sequentially entering a market get the same profit, and there is no leader advantage. This goes against the widely held belief that some first-mover advantages do exist in reality (Tyagi, 2000).

Before the new firm enters the market, the incumbent is the monopoly in the market. For a monopoly firm positioning at $x$ and pricing at $p$, the valuation of consumers with ideal point $t$ is $R-(x-t)^{2}-p$. Consequently, the total disutility for all consumers $\int_{-0.5}^{0.5}(x-t)^{2} d t=\frac{1}{12}+x^{2}$. The incumbent (monopoly) positions at the best position $x=0$, where the consumers' total disutility is minimized (Makadok \& Ross, 2013).

After the new firm enters the market, the incumbent can move its original position to a new one $x_{i}$, but will incur cost

$$
k\left|x_{i}-0\right|=k\left|x_{i}\right|,
$$

where $k(\geq 0)$ is the repositioning parameter. The repositioning costs described in (1) increase with respect to repositioning distance $\left|x_{i}\right|$. In other words, repositioning costs are distance-based (Montgomery \& Wernerfelt, 1988) and increase with the firm's distance between the origin (the initial position from which the incumbent is moving) and destination (the position to which the incumbent is moving). Such costs account for difficulties in changing the firm's initial activity system, for 
example, difficulties in unwinding and changing current operations and related commitments (Menon \& Dennis, 2017; Sethi \& Sethi, 1990; Upton, 1995).

The parameter $k$ in (1) can represent the incumbent's repositioning ability: the higher $k$ is, the lower the repositioning ability becomes. For example, $k=0$ represents the full flexibility for repositioning that is costless, whereas $k=+\infty$ is the other extreme, that is, the incumbent incurs an infinite cost for repositioning.

Our strategic mental model builds upon the repositioning parameter $k$. We particularly consider the first and the second order beliefs around $k$ because, although the degree of belief iterations can go on ad infinitum in the real-world, strategic actors tend to mostly adhere to their first or second order beliefs (Camerer, Ho, \& Chong, 2015; Menon, 2018). That is, we focus on three different settings as follows.

First, we consider the first order belief of the parameter $k$ in Section 4 , where the incumbent's costs defined by this parameter are not perfectly known by the entrant. In particular, the new entrant is biased and behaves as if the incumbent's repositioning parameter is $\theta k$ rather than $k$ where $\theta \geq 0$. When $\theta<1$ (resp. $\theta>1$ ), the entrant estimates the incumbent's repositioning costs as less (more) than they really are, that is, the entrant overestimates (underestimates) the repositioning ability of the incumbent. The level of the entrant's underestimation bias can be characterized by $\theta-1$, whereas the level of entrant's overestimation bias can be characterized by $1-\theta$. In this way, $|\theta-1|$ indicates the level of entrant bias.

Second, we further investigate a second-order belief of repositioning costs in Section 5. In this setting, the incumbent does not accurately assess entrant bias, despite knowing that such a bias exists. In particular, although entrant bias is captured by the parameter $\theta$, the incumbent assesses the incumbent's parameter as $\theta(\neq \theta)$.

Third, we consider another second order belief of repositioning costs in Section 6, where the incumbent is completely unaware of the entrant's bias. In this setting, the entrant has biased estimates of the incumbent's repositioning ability $(\theta \neq 1)$ while the incumbent is biased in terms of not foreseeing entrant bias, that is, the incumbent assesses the incumbent's parameter as $\theta=1$.

\section{4 | BIASED ENTRANT}

In this section, we develop our strategic mental model with the first order belief of repositioning costs - the entrant is biased and behaves as if the incumbent's repositioning parameter is different from the true parameter. We follow the standard approach in the literature to solve the problem backward by first evaluating firms' pricing decisions and then solving their re/positioning decisions.

We first solve the price competition between firms. After the incumbent chooses her new position, the incumbent and the new entrant decide their prices $p_{i}$ and $p_{e}$ simultaneously so that the firms maximize their own profits. This follows the traditional argument in the literature of position competition (d'Aspremont et al., 1979; Hotelling, 1929; Makadok \& Ross, 2013) that pricing decisions are believed to be more flexible than positioning decisions; price can be easily changed, but it is often difficult to adjust strategy or product positions. Given the incumbent position $x_{i}$ and price $p_{i}$ as well as the entrant position $x_{e}$ and price $p_{e}$, consumers make their purchasing decisions. For the sake of presentation, we present the case where only the new entrant repositions himself to the right of the incumbent $\left(x_{i}<x_{e}\right)$. See Appendix for details.

After solving the game of retail price, we obtain the incumbent repositioning problem: 


$$
\begin{aligned}
& \pi_{i}^{k}\left(x_{e}\right):=\max _{x_{i}}\left(p_{i}-c\right)\left(\frac{1}{2}+\frac{p_{e}-p_{i}}{2\left(x_{e}-x_{i}\right)}+\frac{x_{i}+x_{e}}{2}\right)-k\left|x_{i}\right| \\
& =\max _{x_{i}} \frac{\left(x_{e}-x_{i}\right)\left(3+x_{i}+x_{e}\right)^{2}}{18}-k\left|x_{i}\right| .
\end{aligned}
$$

In solving (2), the incumbent would like to position herself close to position $x=0$ to limit her repositioning costs. Moreover, positioning closer to $x=0$ is more efficient. In addition, if the incumbent can either observe or foresee the entrant's position $x_{e}$, the incumbent also would likely differentiate herself from the entrant for a higher differentiation $\left(x_{e}-x_{i}\right)$. Overall, the incumbent needs to balance repositioning costs, position efficiency, and differentiation to reach the optimal position $x_{i}^{k}$. Next, we characterize the incumbent's optimal position level $x_{i}^{k}$ and her associated profit $\pi_{i}^{k}\left(x_{e}\right)$ in Lemma 1 .

Lemma 1 Given the entrant's position $x_{e}(>0)$ :

a. The incumbent's optimal position is

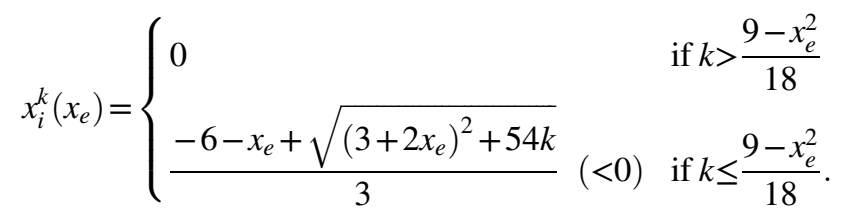

Moreover, $\frac{\partial x_{i}^{k}\left(x_{e}\right)}{\partial k}>0$ and $\frac{\partial x_{i}^{k}\left(x_{e}\right)}{\partial x_{e}}>0$ when $k \leq \frac{9-x_{e}^{2}}{18}$.

b. The incumbent's optimal profit $\pi_{i}^{k}\left(x_{e}\right)$ satisfies $\frac{\partial \pi_{i}^{k}\left(x_{e}\right)}{\partial k}<0$ and $\frac{\partial \pi_{i}^{k}\left(x_{e}\right)}{\partial x_{e}}>0$.

Lemma 1a shows that when the entrant enters the market, it is optimal for the incumbent to remain at her original position if the repositioning parameter is relatively high $\left(k>\frac{9-x_{e}^{2}}{18}\right)$, that is, the repositioning ability is low. However, when the repositioning parameter is relatively low $\left(k \leq \frac{9-x_{e}^{2}}{18}\right)$, the incumbent repositions herself, distancing herself from the entrant for a higher differentiation in order to lessen price competition; that is, $x_{i}^{k}\left(x_{e}\right)<0$. Moreover, the closer the entrant is to the incumbent's original position, the higher the magnitude of the incumbent's repositioning $\left|x_{i}^{k}\left(x_{e}\right)\right|=-x_{i}^{k}\left(x_{e}\right)$. That is, $\frac{\partial x_{i}^{k}\left(x_{e}\right)}{\partial x_{e}}>0$. For the entrant, positioning away from the incumbent's original position $(x=0)$ results in less competition for the incumbent, lowering the incumbent's incentive to reposition. Moreover, for a given incumbent position $x_{e}$, the incumbent's new position $x_{i}^{k}\left(x_{e}\right)$ always increases in her repositioning parameter $k$, that is, $\frac{\partial x_{i}^{k}\left(x_{e}\right)}{\partial k}>0$ : the higher the repositioning parameter, the lower the magnitude of repositioning $\left|x_{i}^{k}\left(x_{e}\right)\right|$. Lemma $1 \mathrm{~b}$ shows that the incumbent's optimal profit increases in the entrant's position $x_{e}\left(\frac{\partial \pi_{i}^{k}\left(x_{e}\right)}{\partial x_{e}}>0\right)$. In this context, a higher entrant position means a greater distance from the incumbent's position, benefiting the incumbent. Moreover, Lemma $1 \mathrm{~b}$ shows that the incumbent's profit decreases in her own repositioning parameter $\left(\frac{\partial \pi_{i}^{k}\left(x_{e}\right)}{\partial k}<0\right)$, which means the incumbent benefits from her own repositioning ability: the higher her repositioning ability, the higher her profit, given the entrant's position. 
We then solve the problem of the biased entrant. In particular, given the incumbent's repositioning parameter $k$, the biased entrant characterized by the bias parameter $\theta$ anticipates the incumbent's repositioning decision as

$$
x_{i}^{\theta k}\left(x_{e}\right)=\left\{\begin{array}{lc}
0 & \text { if } k>\frac{9-x_{e}^{2}}{18 \theta} \\
\frac{-6-x_{e}+\sqrt{\left(3+2 x_{e}\right)^{2}+54 \theta k}}{3}(<0) & \text { if } k \leq \frac{9-x_{e}^{2}}{18 \theta},
\end{array}\right.
$$

although the incumbent's decision is actually characterized by (3). As a result, the entrant solves

$$
\max _{x_{e}} \frac{\left[x_{e}-x_{i}^{\theta k}\left(x_{e}\right)\right]\left[3-x_{i}^{\theta k}\left(x_{e}\right)-x_{e}\right]^{2}}{18}
$$

for his optimal position $x_{e}(\theta)$, that is, the solution of (4). Given this, from (3), the incumbent's new position is

$$
x_{i}(\theta):=x_{i}^{k}\left(x_{e}(\theta)\right)=\left\{\begin{array}{lc}
0 & \text { if } k>\frac{9-x_{e}(\theta)^{2}}{18} \\
\frac{-6-x_{e}(\theta)+\sqrt{\left[3+2 x_{e}(\theta)\right]^{2}+54 k}}{3}(<0) & \text { if } k \leq \frac{9-x_{e}(\theta)^{2}}{18} .
\end{array}\right.
$$

We start with the case where the incumbent knows the entrant's position $x_{e}^{k}(\theta)$ before repositioning. In practice, such knowledge can be obtained from direct observation of the entrant's strategic position. When the entrant's position is unobserved to the incumbent, she may foresee the entrant's position, which reflects an awareness of the entrant bias and an accurate assessment of the level of entrant bias. We relax our assumption later in Sections 5 and 6.

Next, we evaluate the equilibrium profits for the incumbent and the entrant. Given the equilibrium positions $x_{e}(\theta)$ and $x_{i}(\theta)$ along with (2), the entrant's equilibrium profit and the incumbent's equilibrium profit are

$$
\pi_{e}(\theta):=\frac{\left[x_{e}(\theta)-x_{i}^{k}\left(x_{e}(\theta)\right)\right]\left[3-x_{i}^{k}\left(x_{e}(\theta)\right)-x_{e}(\theta)\right]^{2}}{18}
$$

and

$$
\pi_{i}(\theta):=\pi_{i}^{k}\left(x_{e}(\theta)\right)=\max _{x_{i}} \frac{\left[x_{e}(\theta)-x_{i}\right]\left[3+x_{i}+x_{e}(\theta)\right]^{2}}{18}-k\left|x_{i}\right|
$$

respectively. Although the entrant behaves as if he is solving (4) for his optimal decision, the entrant's profit is characterized by (6) rather than (4). Moreover, although the incumbent is not biased, her equilibrium profit can be affected by the bias parameter $\theta$ via the entrant's biased decision $x_{e}(\theta)$.

We next evaluate the impacts of repositioning costs and the entrant bias on the equilibrium profits in (6) and (7). 
Repositioning costs. For insights on the repositioning costs, we first present a baseline model where the entrant is unbiased $(\theta=1)$. More importantly, this special case also serves as a benchmark for our key results (Propositions 2 and 4).

Anticipating the incumbent's repositioning strategy, the new entrant accordingly decides his position. If the new entrant perfectly foresees the incumbent's repositioning parameter $(k)$, then he is able to infer the incumbent's repositioning strategy described in (3). Consequently, the entrant's profit becomes

$$
\begin{aligned}
& \pi_{e}^{k}:=\max _{x_{e}}\left(p_{e}-c\right)\left(\frac{1}{2}-\frac{p_{e}-p_{i}}{2\left(x_{e}-x_{i}\right)}-\frac{x_{i}+x_{e}}{2}\right) \\
& =\max _{x_{e}} \frac{\left[x_{e}-x_{i}^{k}\left(x_{e}\right)\right]\left[3-x_{i}^{k}\left(x_{e}\right)-x_{e}\right]^{2}}{18},
\end{aligned}
$$

where $x_{i}^{k}\left(x_{e}\right)$ is from (3). Like the incumbent, the entrant needs to differentiate himself from his rival (the incumbent) while attempting to position himself close to an efficient position. Moreover, the entrant strategically anticipates that his position decision can affect the incumbent's repositioning decision (Lemma 1). Thus, although the entrant does not incur repositioning costs directly, his equilibrium position $x_{e}^{k}$ and the ensuing profit $\pi_{e}^{k}$ are affected by the incumbent's repositioning parameter $k$. Next, we characterize the entrant's equilibrium position $x_{e}^{k}$ and equilibrium profit $\pi_{e}^{k}$ in Lemma 2.

Lemma 2 (a)Let $x_{e}^{k}$ denote the solution of (8) for any given $k$. Then, there exists a repositioning parameter $k$ such that $x_{e}^{k}=1$ for $k>k$, whereas $x_{e}^{k}$ increases in $k$ for $k \leq k$.

(b)When $k>k$, the entrant's equilibrium profit $\pi_{e}^{k}=\frac{2}{9}$. However, when $k<k, \pi_{e}^{k}$ decreases in $k$.

Lemma 2a characterizes the entrant's equilibrium position $x_{e}^{k}$ and how it changes with the repositioning parameter $k$; see Figure 1 for an illustration. For a relatively large repositioning parameter such that $k>k$, repositioning does not happen. Thus, the entrant's position $x_{e}^{k}(=1)$ is independent of the repositioning parameter $k$. However, for a relatively small repositioning parameter such that $k<k$, the incumbent repositions with a new position which increases in $k$. In other words, as repositioning becomes easier ( $k$ is smaller), the entrant's position $x_{e}^{k}$ becomes closer to (or less differentiated from) the incumbent's original position $x=0$. In the extreme of costless repositioning $(k=0)$, the entrant positions himself at the incumbent's original position $x_{e}^{k}=0$ by anticipating the incumbent's repositioning behavior. The repositioning parameter $k$ is the value where the incumbent is indifferent to both the non-repositioning strategy and the repositioning strategy. However, as shown in Figure 1, the entrant's position jumps as the incumbent switches from a repositioning strategy to a non-repositioning strategy, that is, $x_{e}^{k^{-}}<x_{e}^{k^{+}}$. As the incumbent switches from a repositioning strategy to a non-repositioning strategy around $k$, the entrant's positioning decision is affected significantly. This observation helps explain the forthcoming results.

Lemma $2 \mathrm{~b}$ demonstrates that the entrant's profit $\pi_{e}^{k}=\frac{2}{9}$ is independent of the incumbent's repositioning costs when the repositioning parameter is high such that $k>k$; see Figure 1 for an illustration. When her repositioning parameter is high, the incumbent does not reposition herself and does not incur repositioning costs (Lemma 2a). However, when the repositioning parameter is low $(k<k)$, the incumbent repositions herself and the entrant's profit decreases in $k$. Stated differently, a higher repositioning ability of the incumbent can translate to a higher profit for the entrant. This is 


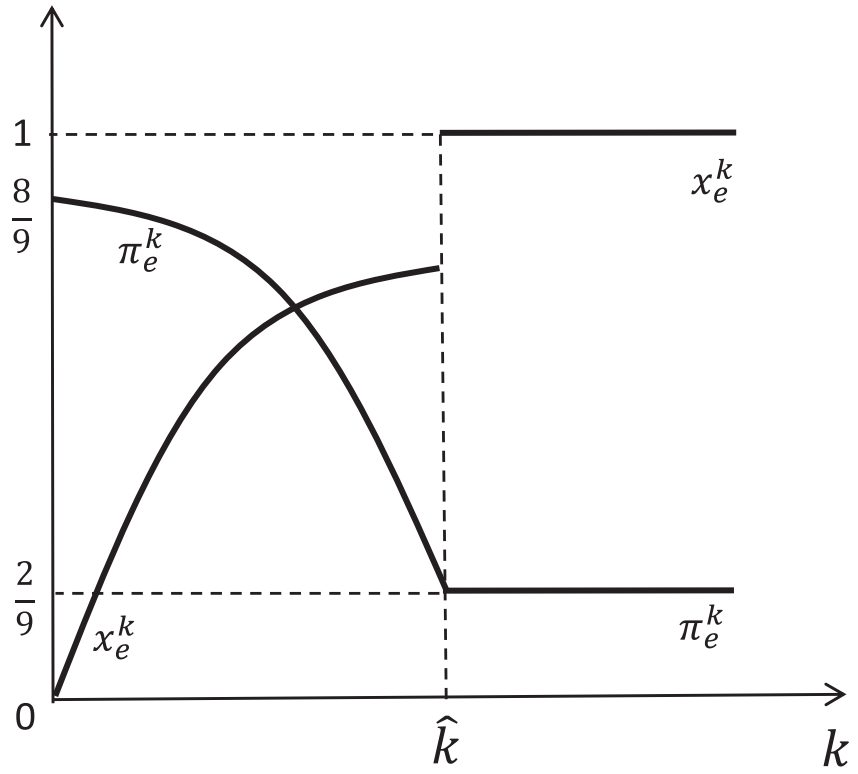

F I G URE 1 The equilibrium position $x_{e}^{k}$ and profit $\pi_{e}^{k}$ for the entrant

somewhat counter-intuitive in the sense that one may expect that the entrant is better off when his rival, the incumbent, becomes weaker in terms of repositioning ability. When the incumbent's repositioning ability is relatively low, the incumbent tends to move away from her current (i.e., the most efficient) position, leaving the entrant a relatively efficient position. Indeed, in the extreme of costless repositioning $(k=0)$, the entrant's profit reaches the maximal value $\pi_{e}^{k}=\frac{8}{9}$, as shown in Figure 1.

Given the entrant's equilibrium position and profit, we now turn our attention to the incumbent's equilibrium decision. From (3) and Lemma 2, the incumbent's equilibrium position is

$$
x_{i}^{k}:= \begin{cases}0 & \text { if } k>k \\ \frac{-6-x_{e}^{k}+\sqrt{\left(3+2 x_{e}^{k}\right)^{2}+54 k}}{3} & \text { if } k \leq k .\end{cases}
$$

That is, when the incumbent chooses to reposition herself $(k \leq k)$, her equilibrium reposition depends on the entrant's repositioning $x_{e}^{k}$. This means that the repositioning parameter affects her own positioning decision not only directly as indicated in Lemma 1, but also indirectly via the entrant positioning $x_{e}^{k}$. Lemma 3 characterizes how $x_{i}^{k}$ and the incumbent equilibrium profit $\pi_{i}^{k}:=\pi_{i}^{k}\left(x_{e}^{k}\right)$, where $\pi_{i}^{k}(\cdot)$ and $x_{e}^{k}$ are defined in (2) and Lemma 2 respectively, are affected by the repositioning parameter $k$.

Lemma 3 (a)The incumbent's equilibrium position $x_{i}^{k}$ increases in $k$ when $k<k$.

(b)The incumbent's equilibrium profit $\pi_{i}^{k}=\frac{8}{9}$ when the incumbent's repositioning parameter is relatively high $(k>k)$. However, $\pi_{i}^{k}$ can increase in $k$ when the incumbent's repositioning parameter is relatively low $(k \leq k)$. 
Lemma 3a shows that when repositioning occurs $(k<k)$, the larger the repositioning parameter, the smaller the repositioning magnitude $\left|x_{i}^{k}\right|$. That is, the incumbent's equilibrium position $x_{i}^{k}$ increases in $k$. This result is qualitatively consistent with Lemma 2, where the entrant position is exogenous, albeit for an additional driver. In the case of an exogenous entrant position, the incumbent is reluctant to reposition herself because of the high costs associated with a high $k$. But when the entrant's position is endogenous, the entrant would position himself away from the incumbent with a higher repositioning parameter, putting less pressure on the incumbent. The low repositioning ability renders a less competitive environment, and consequently less incentive for the incumbent to differentiate. Lemma $3 b$ states when the incumbent does not reposition herself $(k>k)$, her profit $\pi_{i}^{k}=\frac{8}{9}$ is independent of the repositioning parameter $k$. Moreover, in contrast to Lemma 1 , Lemma $3 \mathrm{~b}$ shows that in equilibrium with an endogenous entrant's position, the incumbent can be better off for a relatively higher $k$ when $k \leq k$; a lower repositioning ability can imply a higher incumbent profit. Intuitively, recall that a relatively high repositioning parameter $k$ would render a less competitive environment for the incumbent. The magnitude of this benefit, due to reduced competition, can be higher than the losses due to higher repositioning costs. To illustrate, recall that the incumbent's switch from a repositioning strategy to a non-repositioning strategy can significantly affect the entrant's positioning decision for a small increase in $k$ around $k$. As a result, the incumbent can be better off as $k$ increases. This insight that an inflexible commitment can bestow advantages on a firm has had a storied tradition in business strategy (Ghemawat, 1991) along with the application of game theory to social sciences and economics (e.g., Chatain \& Zemsky, 2007; Schelling, 1980; Sutton, 1991). This insight is further elaborated in Menon and Dennis (2017), who analyze the interaction between an incumbent (innovator) and an entrant (follower) involving repositioning costs. We extend this insight in a different yet important setting, where the incumbent incurs repositioning costs after a competitive entry (Seamans \& Zhu, 2017; Wang \& Shaver, 2014).

After characterizing the entrant and incumbent's respective profits, we evaluate the incumbent's performance relative to the new entrant, that is, $\Delta^{k}:=\pi_{i}^{k}-\pi_{e}^{k}$. In our setting, the incumbent firm is the leader of the market, and she has a pioneering advantage in the sense that the incumbent initially positions herself at the best market location. However, the incumbent can have lower performance than the entrant.

Corollary 1 When $k>k$, the incumbent earns more profit than the entrant, that is, $\Delta^{k}>0$. However, when $k \leq k$, the incumbent can earn less profit than the entrant, that is, $\Delta^{k}<0$.

Corollary 1 demonstrates that when the repositioning parameter is relatively high $(k>k)$, the leader advantage prevails. Because the incumbent initially occupies the best market location, her first-mover advantage remains as the repositioning parameter is high. However, when the repositioning parameter is relatively small $(k \leq k)$, although the incumbent firm is more operationally efficient at repositioning, her leader advantage can disappear because, if repositioning occurs, the incumbent positions herself at a less efficient location than the entrant does. One implication of this result is that $\Delta^{k}$ can decrease in $k$ as $k$ becomes higher. Counterintuitively, the incumbent's low repositioning ability can help her gain relative advantage over her rival.

Entrant bias. Corollary 1 states that the incumbent's leader advantage can disappear when the entrant precisely foresees the incumbent's repositioning decision. This begs the question of how the entrant's foresight affects this result. To explore it, we dive deeper to study the case of a biased entrant $(\theta \neq 1)$. 


\section{Lemma 4 Given the entrant bias parameter $\theta$ :}

(a)The entrant's equilibrium profit $\pi_{e}(\theta)$ decreases in $\theta$ when $\theta>1$, while $\pi_{e}(\theta)$ increases in $\theta$ when $\theta<1$.

(b)The incumbent's profit $\pi_{i}(\theta)$ increases in $\theta$.

Lemma 4a shows that the entrant's profit $\pi_{e}(\theta)$ decreases in the bias parameter $\theta$ when the entrant has an underestimation bias $(\theta>1)$, but increases in the bias parameter $\theta$ when the entrant has an overestimation bias $(\theta<1)$. Consequently, regardless of the type of bias, the entrant's profit decreases in the level of bias $(|\theta-1|)$. However, Lemma $4 \mathrm{~b}$ shows that the incumbent's profit increases in the bias parameter $\theta$. Essentially, the incumbent prefers the entrant to choose a position that is distant from her because her profits increase with differentiation. When the entrant underestimates the incumbent's repositioning ability, he distances himself from the incumbent and the incumbent thus benefits from the greater differentiation. Similarly, when the entrant overestimates the incumbent's repositioning ability, he locates himself close to the incumbent hoping the incumbent will reposition herself farther away. Therefore, we check whether the entrant's bias can lead to a higher relative performance for the entrant.

Corollary 2 Define $\hat{\Delta}(\theta):=\hat{\pi}_{i}(\theta)-\hat{\pi}_{e}(\theta)$. Then, when $\theta>1, \hat{\Delta}(\theta)$ increases in the level of the entrant's bias $(\theta-1)$, that is, $\theta>1 \Rightarrow \hat{\Delta} \prime(\theta)>0$. However, when $\theta<1, \hat{\Delta}(\theta)$ can decrease in the level of the entrant's bias $(1-\theta)$.

Corollary 2 demonstrates that the entrant's underestimation bias $(\theta>1)$ always drags down the entrant's relative performance, namely, the follower advantage $-\Delta(\theta)$. However, the entrant's overestimation bias $(\theta<1)$ can boost his relative advantage over the incumbent. For insights, recall that when the entrant overestimates the incumbent's repositioning ability, the biased entrant would like to position himself closer to the incumbent, putting more competition pressure on the incumbent. When this drag on the incumbent is significant and outweighs the entrant's losses due to his decision bias, that is, when the incumbent's profit is more sensitive to entrant bias than entrant profit, the entrant's relative advantage can be enhanced. Thus, overestimation bias can hurt the incumbent even more than it does the entrant, and it is possible that the entrant with the overestimation bias can make more profit than the incumbent even when the unbiased entrant cannot. This is interesting because, given that the unbiased entrant can foresee the incumbent's decision, at the least, the unbiased entrant can mimic the biased entrant's decision and earn the same profit as the biased entrant. However, ironically, Corollary 2 indicates that although the unbiased entrant can increase his own profit by reacting optimally, his optimal reaction nevertheless can increase his competitor's profit even more, depending on the type of entrant bias.

Corollary 2 also implies that the incumbent's low repositioning ability can be a leader advantage when the entrant is biased in (under)estimating the incumbent's repositioning ability. This also means that the entrant (follower) advantage can persist when the entrant has an overestimation bias while the incumbent incurs repositioning costs. We can show that when the incumbent does not incur repositioning costs, the entrant's follower advantage persists as long as his position is closer to the center of the Hotelling line than the incumbent's position (see Appendix for details).

\section{5 | BIASED ENTRANT AND IMPRECISE INCUMBENT}

So far we have assumed that the incumbent is not only aware of entrant bias, but also has a precise assessment of that bias. We now extend our analysis to the case where the incumbent's assessment of 
the entrant bias is inaccurate. In particular, although entrant bias is captured by the parameter $\theta$, the incumbent assesses the entrant's parameter as $\theta(\neq \theta)$. As a result, the entrant described by the bias parameter $\theta$ positions himself at $x_{e}(\theta)$, that is, the solution of (4). However, the incumbent still positions herself at $x_{i}(\theta)$, where $x_{i}(\cdot)$ is from (5). The entrant's equilibrium profit and the incumbent's equilibrium profit are therefore

$$
\pi_{e}(\theta, \theta):=\frac{\left[x_{e}(\theta)-x_{i}(\theta)\right]\left[3-x_{i}(\theta)-x_{e}(\theta)\right]^{2}}{18}
$$

and

$$
\pi_{i}(\theta, \theta):=\frac{\left[x_{e}(\theta)-x_{i}(\theta)\right]\left[3+x_{i}(\theta)+x_{e}(\theta)\right]^{2}}{18}-k\left|x_{i}(\theta)\right|,
$$

respectively. The incumbent's leader advantage is consequently $\Delta(\theta, \theta):=\pi_{i}(\theta, \theta)-\pi_{e}(\theta, \theta)$. We next study the impact of the incumbent's imprecise bias (i.e., the inaccurate assessment of the entrant's behavior) on the firm performances defined in (10) and (11), as we have done before.

Proposition 1 (a)The incumbent's imprecise bias always leads to a lower profit for the incumbent, that is, $\pi_{i}(\theta) \geq \pi_{i}(\theta, \theta)$ for any $\theta$. However, the incumbent's imprecise bias can lead to a higher relative performance for the incumbent, that is, $\Delta(\theta, \theta)>\Delta(\theta)$ when $\theta>\theta$.

(b)The incumbent's imprecise bias hurts the entrant, that is, $\pi_{e}(\theta, \theta)<\pi_{e}(\theta)$ when $\theta>\theta$, but it benefits the entrant, that is, $\pi_{e}(\theta, \theta)>\pi_{e}(\theta)$ when $\theta<\theta$.

Proposition 1a shows that, although incumbent bias always leads to a lower profit for the incumbent, it can actually boost the incumbent's leader advantage - the incumbent's performance relative to the entrant. Although the incumbent's bias hurts the incumbent, it can hurt the entrant even more than it does the incumbent when $\theta>\theta$, thus boosting the incumbent's relative performance. Consequently, incumbent bias can either hurt or benefit her rival (the entrant) depending on the relative value of $\theta$ and $\theta$; entrant bias can also benefit the incumbent (Lemma 4b). This raises the question of whether firms can earn more when they are both biased versus both unbiased.

Proposition 2 Entrant bias and incumbent bias always lead to lower performance for the entrant and incumbent respectively, that is, $\left(\pi_{e}(\theta), \pi_{i}(\theta, \theta)\right) \leq\left(\pi_{e}^{k}, \pi_{i}(\theta)\right)$. However, there exists $\bar{k}$ such that, if $k<\bar{k}$, biased firms can earn more than sophisticated firms, that is, $\left(\pi_{e}(\theta, \theta), \pi_{i}(\theta, \theta)\right)>\left(\pi_{e}^{k}, \pi_{i}^{k}\right)$ when $\theta>1$ and $\theta<\theta$.

Proposition 2 indicates that although biases by themselves are unequivocally harmful for firms, both the entrant and incumbent can be better off when they are biased versus unbiased. That is, each firm can benefit from their simultaneous (but not singular) biases. Consider that in our setting, in addition to repositioning costs incurred by the incumbent, each firm's performance is affected by its relative location, which determines differentiation. When the entrant underestimates the incumbent's repositioning ability $(\theta>1)$, the entrant tends to position himself farther from the incumbent, benefiting the incumbent. At the same time, when the incumbent assesses the level of the entrant bias as lower than it really is $(\theta<\theta)$, incumbent bias can lead to a position away from the entrant, thus 
benefiting the entrant. Consider the case where the repositioning parameter is relatively small $(k<\bar{k})$, say $k=0$, so that the incumbent's loss due to her decision bias is not significant. Then, in our baseline model, the entrant and incumbent's respective equilibrium profits are $\left(\pi_{e}^{k}, \pi_{i}^{k}\right)=\left(\frac{8}{9}, \frac{2}{9}\right)$ with the associated equilibrium positions $\left(x_{e}^{k}, x_{i}^{k}\right)=(0,-1)$. The entrant is hurt by his own bias because $\pi_{e}(\theta) \leq \pi_{e}(\theta=1)=\pi_{e}^{k}$ (Lemma 4). The incumbent's bias always hurts her, too, as seen in $\pi_{i}(\theta, \theta) \leq \pi_{i}(\theta)$, because the rational incumbent optimally chooses her optimal position in order to obtain her optimal profit in (7), but the biased incumbent does not in (11). However, if the entrant expects that the incumbent's repositioning parameter is higher than $k$ with $\theta=\infty$, then the entrant positions at $x_{e}^{k}(\theta)=1$ (Lemma 2), while the incumbent still positions at $x_{i}(\theta)=-1$ when $\theta<\theta$. As a result, from (10) and (11), both the biased entrant and the biased incumbent earn more than unbiased firms, that is, $\left(\pi_{e}(\theta, \theta), \pi_{i}(\theta, \theta)\right)=(1,1)>\left(\frac{8}{9}, \frac{2}{9}\right)=\left(\pi_{e}^{k}, \pi_{i}^{k}\right)$. In this example, we see that the decision biases of the incumbent and the entrant can lead to a situation where firms are well differentiated. Although such differentiation can entail less efficient positions (far from the center of the Hotelling line), thus potentially hurting firms (especially the incumbent incurring repositioning costs), this example illustrates that the benefits of increasing differentiation can offset the losses of firms. This particularly happens when the repositioning parameter is relatively small, while the entrant incurs a significant underestimation bias and the incumbent underassesses the entrant bias.

\section{I BIASED ENTRANT AND UNAWARE INCUMBENT}

In the last section, we investigate the case where the incumbent is biased in assessing the entrant's behavior, that is, the incumbent is partially cognizant in the sense that the incumbent is still aware of entrant bias but has an inaccurate assessment. In this section, we extend our scope to the case with a more biased incumbent who is totally unaware of entrant bias. The objective of this section is twofold. First, we check the robustness of our main insights in Section 5, namely incumbent bias can enhance her relative advantage while hurting the entrant, and decision biases can lead to a mutually beneficial situation for both firms (Propositions 1 and 2). Second, we derive new insights driven by the incremental bias of the unaware (versus aware but imprecise) incumbent.

We now describe the equilibrium outcome when the entrant is biased and the incumbent is unaware of entrant bias. For this case, from (9), the incumbent positions herself at $x_{i}^{k}$ while expecting the entrant's position to be $x_{e}^{k}$. Consequently, the equilibrium positions for the entrant and the incumbent are $x_{e}(\theta)$ and $x_{i}^{k}$, respectively. For this setting where the entrant has biased estimates of the incumbent's repositioning ability $(\theta \neq 1)$ while the incumbent is biased in terms of not foreseeing entrant bias, the entrant's and the incumbent's equilibrium profits are

and

$$
\tilde{\pi}_{e}(\theta):=\frac{\left[x_{e}(\theta)-x_{i}^{k}\right]\left[3-x_{i}^{k}-x_{e}(\theta)\right]^{2}}{18}
$$

$$
\tilde{\pi}_{i}(\theta):=\frac{\left[x_{e}(\theta)-x_{i}^{k}\right]\left[3+x_{i}^{k}+x_{e}(\theta)\right]^{2}}{18}-k\left|x_{i}^{k}\right|,
$$

respectively. Consequently, the incumbent's leader advantage is $\tilde{\Delta}(\theta):=\tilde{\pi}_{i}(\theta)-\tilde{\pi}_{e}(\theta)$. We next study the impact of incumbent bias (unawareness) on firm performances defined in (12) and (13). 
Proposition 3 (a)The incumbent's lack of awareness always leads to a lower profit for the incumbent, that is, $\pi_{i}(\theta) \geq \tilde{\pi}_{i}(\theta)$ for any $\theta$. However, the incumbent's lack of awareness can lead to a higher relative performance for the incumbent, that is, $\tilde{\Delta}(\theta)>\hat{\Delta}(\theta)$.

(b)The incumbent's lack of awareness hurts the entrant, that is, $\tilde{\pi}_{e}(\theta)<\pi_{e}(\theta)$ when $\theta<1$.

Proposition 3 shows that, although a lack of awareness leads to a lower profit for the incumbent, this lack of awareness as a decision bias can actually boost the incumbent's leader advantage while hurting the entrant.

Proposition 4 The entrant's estimation bias and the incumbent's lack of awareness always lead to lower respective performances, that is, $\left(\pi_{e}(\theta), \tilde{\pi}_{i}(\theta)\right) \leq\left(\pi_{e}^{k}, \pi_{i}(\theta)\right)$ for any $\theta$. However, if $\theta>1$ and $k<\bar{k}$, where $\bar{k}$ is defined in Proposition 2, then biased firms can earn more than the sophisticated firms, that is, $\left(\tilde{\pi}_{e}(\theta), \tilde{\pi}_{i}(\theta)\right)>\left(\pi_{e}^{k}, \pi_{i}^{k}\right)$.

Proposition 4 further shows that, when both firms are biased, they can earn more than unbiased firms when the repositioning parameter $k$ is relatively low $(k<\bar{k})$ and the entrant underestimates the incumbent's repositioning ability $(\theta>1)$. Thus, the main insight from the setting where the incumbent has an estimation bias (Proposition 2) continues to hold for a setting where the incumbent has a bias due to a lack of awareness. Given this, we compare the equilibrium profits for these two settings to evaluate the impact of the incumbent's lack of awareness versus estimation bias.

Proposition 5 The increasing bias of the incumbent can benefit both the entrant and the incumbent, that is, $\left(\tilde{\pi}_{e}(\theta), \tilde{\pi}_{i}(\theta)\right)>\left(\pi_{e}(\theta, \theta), \pi_{i}(\theta, \theta)\right)$, when $\theta<1<\theta$.

Proposition 5 shows that both firms can achieve higher profits when the incumbent is unaware of entrant bias than when the incumbent is aware of it (but makes an inaccurate assessment). When the incumbent foresees an overestimation bias $(\theta<1)$, she would expect the entrant to position himself close to her so that the incumbent has more incentive to reposition than when the incumbent is unaware of entrant bias, rendering a less competitive environment and benefiting the entrant. Moreover, when the entrant has an underestimation bias $(\theta>1)$ but the incumbent expects the entrant to have an overestimation bias $(\theta<1)$, the incumbent's estimation of entrant behavior is so biased that the incumbent can be better off by being completely unaware of entrant bias. This means that, interestingly, the incumbent's (increasing) bias can even benefit the incumbent, per se, which differs from our previous result that a firm's own bias always hurts the firm (Lemma 4a, Proposition 1a, and Proposition 3a). Indeed, Proposition 5 shows that with increasing bias the incumbent can benefit both herself and the entrant, depending on the magnitudes of the incumbent bias and entrant bias.

\section{7 | ROBUSTNESS AND EXTENSIONS}

In our analysis of the strategic mental model, we do not intend to be comprehensive in examining all possible biases. Rather, we aim to show that our model can produce valuable implications in an important context. In doing so, we apply the following treatments to either highlight our main 
insights or keep the analysis trackable. (a) The position decisions of firms are open anywhere on the Hotelling line. (b) The entrant moves first, and the incumbent moves next to reposition herself. (c) The entrant's entry cost is zero. (d) The reservation price of consumers $R$ is sufficiently high so that consumers always purchase from firms, that is, the market is fully covered. (e) The production costs for firms are symmetric. (f) The incumbent repositioning cost defined in (1) is linear in the degree of repositioning. (g) Firms operate in a single-period setting so that they do not learn from each other's actions.

To extend the scope of this paper, we relax the above assumptions by developing seven model extensions. ${ }^{1}$ First, we restrict firms so that they locate themselves only inside the unit interval $[-0.5$, 0.5] where consumers are located. That is, neither the entrant nor incumbent is allowed to choose a position outside the unit interval where there are no consumers. Second, we study the case where the incumbent moves first and the entrant is the follower. This means that the incumbent decides her repositioning in anticipation of the competitive entry, after which the entrant decides his position in the market. Third, we set the entrant's entry cost as not negligible. When the entrant enters the market, the entrant incurs a fixed cost. Fourth, we study a case where the market is not necessarily fully covered. The consumer reservation value $R$ is not so large that consumers can be uncovered. Fifth, we consider a case where firms have different production costs. Sixth, we consider the case where the repositioning cost is not linear but quadratic in the magnitude of repositioning. Lastly, we extend our analysis of the single-period model to a two-period setting where firms can infer the rival's biases over time.

In the above model variations, although the technical analysis differs depending on the particular variation, we find that our main insights_-biases by themselves are unequivocally bad for the focal players, but when present together, biased firms can actually outperform the "correct" or sophisticated firms (Propositions 2 and 4) -remain robust. Generally speaking, this is because the key mechanism of Propositions 2 and 4-decision biases can lessen the competition between firms-continues to hold in these model extensions. In particular, when biased firms make position decisions, they can position themselves farther (more differentiated) from each other than unbiased firms can, depending on the type of entrant bias and incumbent bias. Consequently, although decision biases lead to nonoptimal decisions for individual firms, these biases could alleviate firm competition, thus potentially conferring a benefit to firms if the benefits outweigh the losses due to biases. We note that a characterization of conditions for beneficial biases is non-trivial and can be technically challenging.

\section{8 | CONCLUDING REMARKS}

This paper develops a strategic mental model to examine the impacts of incumbent's repositioning costs and associated decision biases within a market entry setting. In our model setting, the entrant is biased on the first order belief, either overestimating or underestimating the incumbent's repositioning ability, whereas the incumbent can also be biased on the second order belief with regard to the entrant's bias, that is, the incumbent is biased in her assessment of entrant bias, despite having an awareness of it. We compare this setting to a baseline setting in which both the incumbent and the entrant are unbiased; the entrant perfectly assesses the incumbent's repositioning ability and the incumbent also knows the entrant's assessment. This comparison reveals that decision biases are not necessarily detrimental for firms, particularly when both the entrant and the incumbent are biased. In a similar vein, when the incumbent is more biased in the sense that she is completely

\footnotetext{
${ }^{1}$ The analysis is available upon request.
} 
unaware of entrant bias, we find that the incumbent's increasing bias can interestingly benefit both herself and the entrant.

Our core argument is that repositioning costs and the associated biases should be central factors to analyses of strategic dynamics in the context of market entry, which in turn has implications for several related literatures. First, this paper contributes to our understanding of how an incumbent responses to new firms entering the market, a central topic in the strategy literature (Ghemawat, 1991; King \& Tucci, 2002; McCann \& Vroom, 2010; Menon \& Dennis, 2017); we enrich this literature by incorporating decision biases of firms, following the lead of Menon (2018). Second, this paper contributes to the research on bias in estimating the skill of others (e.g., see Moore \& Cain, 2007, Goldfarb \& Xiao, 2011, and Cain et al., 2015). Although this literature often states that decision biases are detrimental, we find that a decision bias can be a positive force in the context of market entry and incumbent repositioning, which helps explain the prevalence of decision biases in market entry (Besanko et al., 2009). Third, our study also adds to a long-standing literature concerning differentiation (Alcácer et al., 2015; Dixit \& Stiglitz, 1977; Hotelling, 1929; Thomas \& Weigelt, 2000). This literature traditionally suggests that each firm's equilibrium strategy is to locate itself at one of two ends of the market, opposite its competitor (d'Aspremont et al., 1979). Our model predicts that firms can locate at any position along the Hotelling line, depending on the repositioning costs and decision biases. This helps reconcile the gap between the traditional theory and real-world examples which often reveal that firms are not necessarily located at the ends of the Hotelling line.

Our results also have implications for strategic interactions between multi-divisional firms competing across geographies or product markets. Suppose the incumbent (entrant) has a sister incumbent (brother entrant) owned by the same parent corporation. If the sister incumbent has experience with the entry of the brother entrant, then the incumbent's own repositioning costs can be affected as a result of learning from prior repositioning across sibling units (Alcácer et al., 2015; Alcácer \& Zhao, 2012; Kalnins \& Mayer, 2004; Seamans \& Zhu, 2017). In such a context, our analysis indicates that changed repositioning costs can lead to a lower or higher performance for the incumbent, and a greater or smaller benefit for the entrant than for the incumbent; see Lemma 3 and Corollary 1. Hypothetically, the sister incumbent could also learn the importance of having "sticky" commitments, and thus instead increase her commitment to the current position. In light of our results, researchers and practitioners should look beyond the positive or negative effect of repositioning ability on the focal incumbent firm's absolute performance, which is the primary focus of the existing literature; what they should also consider is the possible negative effect on an incumbent's relative performance vis-á-vis competitive entrants, which is often an important strategic concern for firms.

This paper takes one of the first analytical steps toward examining the impacts of decision biases associated with repositioning costs. While we believe that our results can apply broadly to different types of post-entry repositioning across different contexts, we acknowledge the possibility that our key insights may change in other contexts, and exploring that can drive future research. For example, we focus on one key strategic parameter, repositioning cost, and consequently, the biases we model are around this parameter. Future research can examine the biases associated with other important strategic parameters, such as the promise of different technological trajectories (Wu, Wan, \& Levinthal, 2014), or more broadly, the very existence of certain actors or actions related to mental models (Levinthal, 2011; Menon, 2018). Moreover, we study decision biases on the first order belief and the second order belief regarding repositioning cost. Future research could also examine higher order beliefs.

We also acknowledge that, as is the case with many other strategic mental models, our model can also lead to situations with inconsistency between the observed outcomes and the beliefs of the firms. In practice, firms may simply ignore such inconsistency or deny its validity (Menon, 2018). For such 
firms, the key insights in this paper can directly apply. However, for firms learning from the inconsistency to recalibrate their assessments of the biases, it is often challenging to identify how they should learn from observed outcomes to update their mental model (Menon \& Dennis, 2018). We are able to conduct a preliminary analysis of a two-period dynamic model, where we find that the managerial insights in Propositions 2 and 4 remain robust. Future research may further address this inconsistency issue by examining settings in which the incumbent and entrant interact for longer periods, or focusing on a subset of the problem and equilibria such as self-confirming equilibria (Ryall, 2003), or even exploring conditions in which a firm should resolve the inconsistency versus ignoring it.

On the empirical front, future work could follow approaches in the empirical literature (Galasso \& Simcoe, 2011; Wang \& Shaver, 2014, 2016) to classify different types of decision biases and different repositioning costs and then accordingly determine market entry decisions together with the associated firms' performance. For settings where firms are likely to be biased about each other (e.g., Shleifer, 2000), one may also empirically identify conditions in which decision biases can lead to lower or higher profits. Such an empirical effort would not only test the predictions of the current model, but also offer guidelines for the design and adoption of strategies aimed at enhancing repositioning ability and curtailing executives' biases.

\section{ACKNOWLEDGEMENTS}

We would like to thank the co-editor Alfonso Gambardella, the associate editor Olivier Chatain, and the two anonymous referees for their insightful comments that improved and streamlined this paper. We especially thank the reviewer team for suggesting the models in Sections 5 and 6 . We also received very valuable comments from the conference participants in 2018 SMS Annual Conference Paris. Xianjin Du is supported by the National Natural Science Foundation of China (grants 71521001, 71690235, and 71871076). Authors contributed equally and are listed in alphabetical order. [Correction added on August 27, 2019 after first online publication: The Acknowledgements have been updated to reflect to contribution of the authors.]

\section{ORCID}

Meng Li (D) https://orcid.org/0000-0002-8476-2189

\section{REFERENCES}

Alcácer, J., Dezsö, C., \& Zhao, M. (2015). Location choices under strategic interactions. Strategic Management Journal, 36(2), 197-215.

Alcácer, J., \& Zhao, M. (2012). Local R\&D strategies and multilocation firms: The role of internal linkages. Management Science, 58(4), 734-753.

Aumann, R., \& Brandenburger, A. (1995). Epistemic conditions for Nash equilibrium. Econometrica, 63, 1161-1180.

Barney, J. (1991). Firm resources and sustained competitive advantage. Journal of Management, 17(1), 99-120.

Besanko, D., Dranove, D., Shanley, M., \& Schaefer, S. (2009). Economics of strategy. New York, NY: John Wiley \& Sons.

Cain, D. M., Moore, D. A., \& Haran, U. (2015). Making sense of overconfidence in market entry. Strategic Management Journal, 36(1), 1-18.

Camerer, C. F., Ho, T.-H., \& Chong, J. K. (2015). A psychological approach to strategic thinking in games. Current Opinion in Behavioral Sciences, 3, 157-162.

Carpenter, G. S. (1989). Perceptual position and competitive brand strategy in a two-dimensional, two-brand market. Management Science, 35(9), 1029-1044. 
Chatain, O., \& Zemsky, P. (2007). The horizontal scope of the firm: Organizational tradeoffs vs. buyer-supplier relationships. Management Science, 53(4), 550-565.

Csaszar, F. A., \& Levinthal, D. A. (2016). Mental representation and the discovery of new strategies. Strategic Management Journal, 37(10), 2031-2049.

Cyert, R. M., \& March, J. G. (1963). A behavioral theory of the firm. Englewood Cliffs, NJ: Prentice Hall.

d'Aspremont, C., Jaskold Gabszewicz, J., \& Thisse, J.-F. (1979). On hotelling's "stability in competition". Econometrica, 47(5), 1145-1150.

Dixit, A. (1979). A model of duopoly suggesting a theory of entry barriers. Bell Journal of Economics, 10(1), 20-32.

Dixit, A. K., \& Stiglitz, J. E. (1977). Monopolistic competition and optimum product diversity. American Economic Review, 67(3), 297-308.

Economides, N. (1984). The principle of minimum differentiation revisited. European Economic Review, 24(3), 345-368.

Eggers, J. P., \& Kaplan, S. (2013). Cognition and capabilities: A multi-level perspective. Academy of Management Annals, 7(1), 295-340.

Eisenhardt, K. M., \& Martin, J. A. (2000). Dynamic capabilities: What are they? Strategic Management Journal, 21 (11), 1105-1121.

Ellickson, P. B., Misra, S., \& Nair, H. S. (2012). Repositioning dynamics and pricing strategy. Journal of Marketing Research, 49(6), 750-772.

Galasso, A., \& Simcoe, T. S. (2011). CEO overconfidence and innovation. Management Science, 57(8), 1469-1484.

Gavetti, G. (2012). Perspective-Toward a behavioral theory of strategy. Organization Science, 23(1), $267-285$.

Ghemawat, Pankaj. 1991. Commitment: The dynamic of strategy. The Free Press, New York, NY

Goldfarb, A., \& Xiao, M. (2011). Who thinks about the competition? Managerial ability and strategic entry in US local telephone markets. The American Economic Review, 101(7), 3130-3161.

Goldfarb, A., \& Yang, B. (2009). Are all managers created equal? Journal of Marketing Research, 46(5), 612-622.

Hauser, J. R., \& Shugan, S. M. (2008). Defensive marketing strategies. Marketing Science, 27(1), 88-110.

Hawk, A., Pacheco-De-Almeida, G., \& Yeung, B. (2013). Fast-mover advantages: Speed capabilities and entry into the emerging submarket of Atlantic basin lng. Strategic Management Journal, 34(13), 1531-1550.

Helfat, C. E., \& Martin, J. A. (2015). Dynamic managerial capabilities: Review and assessment of managerial impact on strategic change. Journal of Management, 41(5), 1281-1312.

Helfat, C. E., \& Peteraf, M. A. (2015). Managerial cognitive capabilities and the microfoundations of dynamic capabilities. Strategic Management Journal, 36(6), 831-850.

Hill, C. W. L., \& Rothaermel, F. T. (2003). The performance of incumbent firms in the face of radical technological innovation. Academy of Management Review, 28(2), 257-274.

Horn, J., Lovallo, D., \& Viguerie, P. (2005). Beating the odds in market entry. The McKinsey Quarterly, 4, 34-45.

Hotelling, H. (1929). Stability in competition. The Economic Journal, 39(153), 41-57.

Kalnins, A., \& Mayer, K. J. (2004). Franchising, ownership, and experience: A study of pizza restaurant survival. Management Science, 50(12), 1716-1728.

Kaplan, S. (2011). Research in cognition and strategy: Reflections on two decades of progress and a look to the future. Journal of Management Studies, 48(3), 665-695.

King, A. A., \& Tucci, C. L. (2002). Incumbent entry into new market niches: The role of experience and managerial choice in the creation of dynamic capabilities. Management Science, 48(2), 171-186.

Levinthal, D. A. (2011). A behavioral approach to strategy-What's the alternative? Strategic Management Journal, 32(13), 1517-1523.

Li, M., Petruzzi, N. C., \& Zhang, J. (2016). Overconfident competing newsvendors. Management Science, 63(8), 2637-2646.

Li, M. (2019). Overconfident distribution channels. Production and Operations Management. Forthcoming.

Lieberman, M. B., \& Montgomery, D. B. (1988). First-mover advantages. Strategic Management Journal, 9, 41-58.

Lieberman, M. B., \& Montgomery, D. B. (1998). First-mover (dis) advantages: Retrospective and link with the resource-based view. Strategic Management Journal, 19(12), 1111-1125.

Makadok, R., \& Ross, D. G. (2013). Taking industry structuring seriously: A strategic perspective on product differentiation. Strategic Management Journal, 34(5), 509-532. 
McCann, B. T., \& Vroom, G. (2010). Pricing response to entry and agglomeration effects. Strategic Management Journal, 31(3), 284-305.

Menon, A. (2018). Bringing cognition into strategic interactions: Strategic mental models and open questions. Strategic Management Journal, 39(1), 168-192.

Menon, A., \& Dennis, Y. (2017). Elevating repositioning costs: Strategy dynamics and competitive interactions. Strategic Management Journal, 38(10), 1953-1963.

Menon, A., \& Dennis, Y. (2018). Rationalizing outcomes: Mental-model-guided learning in competitive markets (Harvard Business School Working Paper No. 17-095). Philadelphia, PA: University of Pennsylvania.

Miller, D., \& Chen, M.-J. (1994). Sources and consequences of competitive inertia: A study of the US airline industry. Administrative Science Quarterly, 39, 1-23.

Modigliani, F. (1958). New developments on the oligopoly front. Journal of Political Economy, 66(3), $215-232$.

Montgomery, C. A., \& Wernerfelt, B. (1988). Diversification, Ricardian rents, and Tobin's q. The Rand Journal of Economics, 19(4), 623-632.

Moore, D. A., \& Cain, D. M. (2007). Overconfidence and underconfidence: When and why people underestimate (and overestimate) the competition. Organizational Behavior and Human Decision Processes, 103(2), 197-213.

Pacheco-de Almeida, G., \& Zemsky, P. (2007). The timing of resource development and sustainable competitive advantage. Management Science, 53(4), 651-666.

Pacheco-De-Almeida, G., Henderson, J. E., \& Cool, K. O. (2008). Resolving the commitment versus flexibility tradeoff: The role of resource accumulation lags. Academy of Management Journal, 51(3), 517-536.

Pascale, R. T., \& Christiansen, E. T. (1989). Honda. Cambridge, MA: Harvard Business Press.

Porac, J. F., Thomas, H., \& Baden-Fuller, C. (1989). Competitive groups as cognitive communities: The case of Scottish knitwear manufacturers. Journal of Management Studies, 26(4), 397-416.

Prescott, E. C., \& Visscher, M. (1977). Sequential location among firms with foresight. The Bell Journal of Economics, $8(2), 378-393$.

Ravi Kumar, K., \& Sudharshan, D. (1988). Defensive marketing strategies: An equilibrium analysis based on decoupled response function models. Management Science, 34(7), 805-815.

Rumelt, R. P., \& Teece, D. J. (1994). Fundamental issues in strategy: A research agenda. Cambridge, MA: Harvard Business Press.

Ryall, M. D. (2003). Subjective rationality, self-confirming equilibrium, and corporate strategy. Management Science, 49(7), 936-949.

Schelling, T. C. (1980). The strategy of conflict. Cambridge, MA: Harvard Business Press.

Schwenk, C. R. (1984). Cognitive simplification processes in strategic decision-making. Strategic Management Journal, 5(2), 111-128.

Seamans, R., \& Zhu, F. (2017). Repositioning and cost-cutting: The impact of competition on platform strategies. Strategy Science, 2(2), 83-99.

Sethi, A. K., \& Sethi, S. P. (1990). Flexibility in manufacturing: A survey. International Journal of Flexible Manufacturing Systems, 2(4), 289-328.

Shleifer, A. (2000). Inefficient markets: An introduction to behavioural finance. Oxford, England: Oxford University Press.

Simon, D. (2005). Incumbent pricing responses to entry. Strategic Management Journal, 26(13), 1229-1248.

Simon, H. A. (1976). Administrative behavior: A study of decision-making processes in administrative organization. New York, NY: Macmillan.

Stalk, G., Jr., \& Lachenauer, R. (2004). Hardball: Five killer strategies for trouncing the competition. Harvard Business Review, 82(4), 62.

Sutton, J. (1991). Sunk costs and market structure: Price competition, advertising, and the evolution of concentration. Cambridge, MA: MIT Press.

Tabuchi, T., \& Thisse, J.-F. (1995). Asymmetric equilibria in spatial competition. International Journal of Industrial Organization, 13(2), 213-227.

Thomas, L., \& Weigelt, K. (2000). Product location choice and firm capabilities: Evidence from the US automobile industry. Strategic Management Journal, 21(9), 897-909.

Trout, J., \& Ries, A. (1982). Positioning: The battle for your mind. New York, NY: McGraw-Hill.

Tyagi, R. K. (2000). Sequential product positioning under differential costs. Management Science, 46(7), 928-940. 
Upton, D. M. (1995). Flexibility as process mobility: The management of plant capabilities for quick response manufacturing. Journal of Operations Management, 12(3), 205-224.

Wang, R. D., \& Shaver, J. M. (2014). Competition-driven repositioning. Strategic Management Journal, 35(11), $1585-1604$.

Wang, R. D., \& Shaver, J. M. (2016). The multifaceted nature of competitive response: Repositioning and new product launch as joint response to competition. Strategy Science, 1(3), 148-162.

Wu, B., Wan, Z., \& Levinthal, D. A. (2014). Complementary assets as pipes and prisms: Innovation incentives and trajectory choices. Strategic Management Journal, 35(9), 1257-1278.

Yoffie, David B. 2014. Mobileye: The future of driverless cars. Harvard Business School Case 715-421.

Zajac, E. J., \& Bazerman, M. H. (1991). Blind spots in industry and competitor analysis: Implications of interfirm (mis) perceptions for strategic decisions. Academy of Management Review, 16(1), 37-56.

Zhang, J., Gou, Q., Liang, L., \& Huang, Z. (2013). Supply chain coordination through cooperative advertising with reference price effect. Omega, 41(2), 345-353.

How to cite this article: $\mathrm{Du} \mathrm{X}, \mathrm{Li} \mathrm{M}, \mathrm{Wu} \mathrm{B}$. Incumbent repositioning with decision biases. Strat Mgmt J. 2019;40:1984-2010. https://doi.org/10.1002/smj.3047

\section{APPENDIX A : PROOFS AND DERIVATIONS}

Justification of (2). Given $x_{i}<x_{e}$, the consumers with ideal point $t$ such that $R-\left(x_{i}-t\right)^{2}-p_{i}>R-\left(x_{e}-t\right)^{2}-p_{e} \Leftrightarrow t<\frac{p_{e}-p_{i}}{2\left(x_{e}-x_{i}\right)}+\frac{x_{i}+x_{e}}{2}$ purchase from the incumbent. Otherwise, consumer purchase from the entrant. Consequently, the demand of the incumbent firm $D_{i}$ and the demand for the new entrant $D_{e}$ are

$$
\left(D_{i}, D_{e}\right)=\left(\frac{1}{2}+\frac{p_{e}-p_{i}}{2\left(x_{e}-x_{i}\right)}+\frac{x_{i}+x_{e}}{2}, \frac{1}{2}-\frac{p_{e}-p_{i}}{2\left(x_{e}-x_{i}\right)}-\frac{x_{i}+x_{e}}{2}\right)
$$

The incumbent and the entrant's pricing problems are therefore

$$
\max _{p_{i}}\left(p_{i}-c\right)\left(\frac{1}{2}+\frac{p_{e}-p_{i}}{2\left(x_{e}-x_{i}\right)}+\frac{x_{i}+x_{e}}{2}\right) \text { and } \max _{p_{e}}\left(p_{e}-c\right)\left(\frac{1}{2}-\frac{p_{e}-p_{i}}{2\left(x_{e}-x_{i}\right)}-\frac{x_{i}+x_{e}}{2}\right)
$$

respectively, where $c(\geq 0)$ is the unit production cost for both firms. Solving (A.2), we obtain equilibrium prices and demands for the incumbent and the new entrant:

$$
\left(p_{i}, p_{e}\right)=\left(c+\frac{\left(x_{e}-x_{i}\right)\left(3+x_{i}+x_{e}\right)}{3}, c+\frac{\left(x_{e}-x_{i}\right)\left(3-x_{i}-x_{e}\right)}{3}\right) .
$$

Note that the profit margins of both firms $p_{i}-c$ and $p_{e}-c$ increase in their position difference $x_{e}-x_{i}$, which means that differentiation between positions has a potential to boost the margins, and consequently profits for both firms.

We now justify (A.3). When $x_{i} \leq \underline{x_{e}}$, the equilibrium prices of the incumbent and entrant are $\left(p_{i}, p_{e}\right)=\left(c+\frac{\left(x_{e}-x_{i}\right)\left[3+\left(x_{i}+x_{e}\right)\right]}{3}, c+\frac{\left(x_{e}-x_{i}\right)\left[3-\left(x_{i}+x_{e}\right)\right]}{3}\right)$ with associated demands $\left(D_{i}, D_{e}\right)=$ $\left(\frac{1}{2}+\frac{x_{i}+x_{e}}{6}, \frac{1}{2}-\frac{x_{i}+x_{e}}{6}\right)$. When $\quad \underline{x_{i}} \geq \underline{x_{e}}$, the equilibrium prices are $\left(p_{i}, p_{e}\right)=$ 
$\left(c+\frac{\left(x_{i}-x_{e}\right)\left[3-\left(x_{i}+x_{e}\right)\right]}{3}, c+\frac{\left(x_{i}-x_{e}\right)\left[3+\left(x_{i}+x_{e}\right)\right]}{3}\right)$ with associated demands $\left(D_{i}, D_{e}\right)=\left(\frac{1}{2}-\frac{x_{i}+x_{e}}{6}, \frac{1}{2}+\frac{x_{i}+x_{e}}{6}\right)$. For this case, the incumbent's profit is

$$
\frac{\left(x_{i}-x_{e}\right)\left(3-x_{i}-x_{e}\right)^{2}}{18}-k\left|x_{i}\right|,
$$

while the entrant's profit is

$$
\frac{\left(x_{i}-x_{e}\right)\left(3+x_{i}+x_{e}\right)^{2}}{18} .
$$

For both cases, $x_{i}+x_{e} \leq 3$ holds for non-trivial equilibria with non-negative demands. This is indeed the case and is checked in the proof of Lemma 3.

From (A.2) and (A.3), we can conclude.

Proof of Lemma 1 (a)In this proof, we present the details only for the case $x_{e}>0$, and $x_{e}<0$ follows a similar proof.

We first prove that the incumbent's optimal position is such that $x_{i} \leq 0$ when $x_{e}>0$. By contradiction, suppose that the incumbent's optimal decision $x_{i}>0$ when $x_{e}>0$. We then have two possible cases: (a) $x_{i}<x_{e}$ and (b) $x_{i}>x_{e}$. For case (a), the incumbent's profit in (2) becomes $\frac{\left(x_{e}-x_{i}\right)\left(3+x_{i}+x_{e}\right)^{2}}{18}-k x_{i}$. However, given $x_{i}>0$, the incumbent can be better off by positioning at $-x_{i}\left(<x_{e}\right) \quad$ with the associated profit $\frac{\left(x_{e}+x_{i}\right)\left(3-x_{i}+x_{e}\right)^{2}}{18}-k x_{i}$, because $\frac{\left(x_{e}+x_{i}\right)\left(3-x_{i}+x_{e}\right)^{2}}{18}-k x_{i}$ $-\left[\frac{\left(x_{e}-x_{i}\right)\left(3+x_{i}+x_{e}\right)^{2}}{18}-k x_{i}\right]=\frac{x_{i}\left(9+x_{i}^{2}-x_{e}^{2}\right)}{9}>0$, where the inequality follows from $x_{i}+x_{e} \leq 3$. For case (ii), the incumbent's profit in (A.4) becomes $\frac{\left(x_{i}-x_{e}\right)\left(3-x_{i}-x_{e}\right)^{2}}{18}-k x_{i}$ which is less than the incumbent profit $\left(\frac{\left(x_{e}+x_{i}\right)\left(3-x_{i}+x_{e}\right)^{2}}{18}-k x_{i}\right)$ by positioning at $-x_{i}$.

We now derive the incumbent's optimal decision. When $x_{e}>0\left(\Rightarrow x_{i} \leq 0\right)$ the objective function of (2) becomes $\frac{\left(x_{e}-x_{i}\right)\left(3+x_{i}+x_{e}\right)^{2}}{18}+k x_{i}$, which is concave in $\mathrm{x}_{\mathrm{i}}$ with the first-order-condition $k=\frac{\left(3+x_{e}+x_{i}\right)\left(3-3 x_{i}-x_{e}\right)}{18} \Rightarrow x_{i}=\frac{-6-x_{e}+\sqrt{\left(3+2 x_{e}\right)^{2}+54 k}}{3}$. The solution $x_{i}=\frac{-6-x_{e}-\sqrt{\left(3+2 x_{e}\right)^{2}+54 k}}{3}$ does not satisfy $x_{i}+x_{e} \leq 3$, and $\frac{-6-x_{e}+\sqrt{\left(3+2 x_{e}\right)^{2}+54 k}}{3} \leq 0 \Leftrightarrow k \leq \frac{9-x_{e}^{2}}{18}$. The incumbent's optimal solution is consequently characterized by (3). Moreover, $\frac{-6-x_{e}+\sqrt{\left(3+2 x_{e}\right)^{2}+54 k}}{3}$ increases in $\mathrm{k}$ and $\mathrm{x}_{\mathrm{e}}$, respectively.

(b)For any $x_{i}$, the objective function in (2) decreases in $k$. From the envelope theorem, the incumbent's optimal profit then also decreases in $k$, that is, $\frac{\partial \pi_{i}^{k}\left(x_{e}\right)}{\partial k}<0$. Moreover, for any $x_{i}$, the derivative of the objective function in (2) with respect to $x_{e} \frac{\left(3+x_{i}+x_{e}\right)\left(3+3 x_{e}-x_{i}\right)}{18}$ is positive because $x_{i}+x_{e} \leq 3 \Rightarrow x_{i} \leq 3$. Consequently, from the envelope theorem, the incumbent's optimal profit also increases in $x_{e}$, that is, $\frac{\partial \pi_{i}^{k}\left(x_{e}\right)}{\partial x_{e}}>0$.

Proof of Lemma 2 (a) If the incumbent does not reposition herself $\left(k \geq \frac{9-x_{e}^{2}}{18}\right)$, then the entrant's profit in (8): $\pi_{e}^{k}=\max _{x_{e}} \frac{x_{e}\left(3-x_{e}\right)^{2}}{18}=\frac{2}{9}$ with the equilibrium entrant position $x_{e}^{k}=1$. However, if the 
incumbent repositions herself $\left(k<\frac{9-x_{e}^{2}}{18}\right)$, then the entrant's profit in (8) becomes $\pi_{e}\left(k, x_{e}\right)=\frac{1}{18}\left[x_{e}-\frac{\sqrt{54 k+\left(2 x_{e}+3\right)^{2}}-x_{e}-6}{3}\right]\left[3-x_{e}-\frac{\sqrt{54 k+\left(2 x_{e}+3\right)^{2}}-x_{e}-6}{3}\right]^{2}$ from (3). Here, $\pi_{e}\left(k, x_{e}\right)$ is supermodular in $k$ and $x_{e}$, that is, $\frac{\partial \pi_{e}\left(k, x_{e}\right)}{\partial x_{e} \partial k}=\frac{18\left[k\left(2 x_{e}-9\right)+4 x_{e}+6\right]}{\left[54 k+\left(2 x_{e}+3\right)^{2}\right]^{3 / 2}}>0$, because $6+4 x_{e}+$ $k\left(2 x_{e}-9\right)>\frac{x_{e}\left[x_{e}\left(9-2 x_{e}\right)+90\right]}{18}+\frac{3}{2}>0$ from $x_{i}+x_{e}<3$ and $k<\frac{9-x_{e}^{2}}{18}$. The entrant equilibrium position $x_{e}^{k}$ therefore increases in $\mathrm{k}$ when the incumbent repositions herself. For a special case of $k=0$, the entrant's equilibrium profit is $\max _{x_{e}} \frac{\left(x_{e}-\frac{x_{e}-3}{3}\right)\left(3-\frac{x_{e}-3}{3}-x_{e}\right)}{18}=\frac{8}{9}$ with the associated entrant position $x_{e}^{k}=0$ from $x_{i}^{k}\left(x_{e}\right)=\frac{x_{e}-3}{3}$ (Lemma 1a).

We now establish the existence of $k$. First, the incumbent repositions (does not reposition) herself when $k=0(k=\infty)$. Second, suppose there exist repositioning parameters $k_{1}$ and $k_{2}\left(>k_{1}\right)$ such that the incumbent repositions (does not reposition) herself when $k=k_{2}\left(k=k_{1}\right)$. Then, $k_{1} \geq \frac{9-\left(x_{e}^{k_{1}}\right)^{2}}{18}$ while $k_{2}<\frac{9-\left(x_{e}^{k_{2}}\right)^{2}}{18}$ from Lemma 1a. Consequently, $\frac{9-\left(x_{e}^{k_{1}}\right)^{2}}{18}<k_{1}<k_{2}<\frac{9-\left(x_{e}^{k_{2}}\right)^{2}}{18} \Rightarrow x_{e}^{k_{1}}>x_{e}^{k_{2}}$, which contradicts that $x_{e}^{k}$ increases in $k$.

(b)When the incumbent does not reposition herself $(k>k)$, the entrant's equilibrium profit is $\pi_{e}^{k}=\frac{2}{9}$ from part (a). However, when the incumbent repositions herself $(k \leq k)$, the entrant's profit is $\pi_{e}\left(k, x_{e}\right)=\frac{\left[x_{e}-x_{i}^{k}\left(x_{e}\right)\right]\left[3-x_{i}^{k}\left(x_{e}\right)-x_{e}\right]^{2}}{18}$, where $x_{i}^{k}\left(x_{e}\right)$ is shown as in (3). From $\frac{\partial \pi_{e}\left(k, x_{e}\right)}{\partial x_{i}^{k}\left(x_{e}\right)}=$ $-\frac{\left[3+x_{e}-3 x_{i}^{k}\left(x_{e}\right)\right]\left[3-x_{e}-x_{i}^{k}\left(x_{e}\right)\right]}{18}<0$ and $\frac{\partial x_{i}^{k}\left(x_{e}\right)}{\partial k}>0$ (Lemma 1a), $\pi_{e}\left(k, x_{e}\right)$ decreases in $x_{e}$ for any $k$, implying the entrant's equilibrium profit $\pi_{e}^{k}$ decreases in $k$.

Proof of Lemma 3 (a) From (9), when $k<k, \quad \frac{d x_{i}^{k}}{d k}=\frac{\left(3+2 x_{e}^{k}\right)}{3 \sqrt{\left(3+2 x_{e}^{k}\right)^{2}+54 k}} \frac{d x_{e}^{k}}{d k}-\frac{1}{3} \frac{d x_{e}^{k}}{d k}=$ $\frac{d x_{e}^{k}}{d k}\left(\frac{3+2 x_{e}^{k}}{3 \sqrt{\left(3+2 x_{e}^{k}\right)^{2}+54 k}}-\frac{1}{3}\right)>0, \quad$ because $\quad \frac{d x_{e}^{k}}{d k}>0 \quad($ Lemma $\quad 2) \quad$ and $\quad k<\frac{9-\left(x_{e}^{k}\right)^{2}}{18}<\frac{\left(3+2 x_{e}^{k}\right)^{2}}{18} \Rightarrow$ $\frac{3+2 x_{e}^{k}}{3 \sqrt{\left(3+2 x_{e}^{k}\right)^{2}+54 k}}>\frac{1}{3}$.

Furthermore, in equilibrium, $x_{i}^{k}+x_{e}^{k}<3$ always holds because $x_{i}^{k}+x_{e}^{k}$ increases in $\mathrm{k}$ from $x_{e}^{k}$ increases in $k$ (Lemma 2), while $x_{i}^{k}+x_{e}^{k}=1$ when $k=\infty$.

(b)When $k>k$, the equilibrium positions are $\left(x_{e}^{k}, x_{i}^{k}\right)=(1,0)$ from the proof of Lemma 2. As a result, the incumbent's equilibrium profit $\pi_{i}^{k}=\frac{\left(x_{e}-x_{i}\right)\left(3+x_{i}+x_{e}\right)^{2}}{18}-k\left|x_{i}\right|=\frac{8}{9}$. However, the incumbent's profit $\pi_{i}^{k}$ can increase when $k \leq k$. It is sufficient to consider the repositioning parameter around $k$, where the incumbent does not reposition (repositions) herself when $\mathrm{k}$ is relatively low (high), that is, $k=k^{-}\left(k=k^{+}\right)$. For an instantaneous increase of the repositioning parameter from $k^{-}$to $k^{+}$, the entrant's position significantly increases and $x_{e}^{k^{-}}<x_{e}^{k^{+}}$; see Figure 1. Consequently, as $k$ increases from $k^{-}$to $k^{+}$, the incumbent's equilibrium profit increases around $k$, that is, $\pi_{i}^{k^{+}}\left(x_{e}^{k^{+}}\right)>\pi_{i}^{k^{-}}\left(x_{e}^{k^{-}}\right)$, because $\pi_{i}^{k}\left(x_{e}\right)$ increases in $x_{e}$ (Lemma $1 \mathrm{~b}$ ). 
Proof of Corollary 4 When $k>k$, from the proofs of Lemma 2, $\pi_{i}^{k}=\frac{8}{9}>\pi_{e}^{k}=\frac{2}{9} \Rightarrow \Delta^{k}>0$. When $k \leq k$, it is sufficient to consider $k=0$, where $\pi_{e}^{k}=\frac{8}{9}>\pi_{i}^{k}=\frac{\left(x_{e}-x_{i}\right)\left(3+x_{i}+x_{e}\right)^{2}}{18}-k\left|x_{i}\right|=\frac{2}{9} \Rightarrow \Delta^{k}<0$.

Proof of Lemma 5 (a)We first show that the entrant's profit $\pi_{e}(\theta)$ in (6) is concave in the entrant's position $x_{e}(\theta)$. When the repositioning parameter is relatively low $\left(k<\frac{9-x_{e}^{2}}{18}\right)$, we define $A=\sqrt{54 k+\left(2 x_{e}+3\right)^{2}}$; then $g\left(x_{e}, k\right):=\frac{d^{2} \pi_{e}}{d x_{e}^{2}}=\frac{8\left[729 k^{2}+27 k\left(4 x_{e}\left(A+3 x_{e}\right)-81-6 A\right)+\left(2 x_{e}-3\right)\left(2 x_{e}+3\right)^{2}\left(A+2 x_{e}+3\right)\right]}{81 A^{3}}$ from (5). Furthermore, $\frac{\partial g\left(x_{e}, k\right)}{\partial x_{e}}=\frac{16\left[729 k^{2}\left(4 A+18 x_{e}-9\right)+\left(2 x_{e}+3\right)^{4}\left(A+2 x_{e}+3\right)+27 k\left(2 x_{e}+3\right)\left(4 x_{e}\left(2 A+5 x_{e}+15\right)+3(4 A+69)\right)\right]}{81 A^{5}}>0$, and $\left.g\left(x_{e}, k\right)\right|_{x_{e}=1}=\frac{8[25 \sqrt{54 k+25}+125+27 k(2 \sqrt{54 k+25}+69-27 k)]}{-81(54 k+25)^{3 / 2}}<0$ when $k<\frac{9-x_{e}^{2}}{18} \leq \frac{1}{2}$. That is, $g\left(x_{e}, k\right)<0$ always holds when $k<\frac{9-x_{e}^{2}}{18}$. When the repositioning parameter is relatively high $\left(k \geq \frac{9-x_{e}^{2}}{18}\right)$, the entrant's profit $\frac{x_{e}\left(3-x_{e}\right)^{2}}{18}$ is also concave in $x_{e}$.

We now show that the entrant's position $x_{e}(\theta)$ increases in $\theta$. The entrant's position $x_{e}(\theta)$ increases in $k$ (Lemma 2). The entrant also makes decisions based on $\theta k$ rather than $k$; see (4). The entrant's position $x_{e}(\theta)$ accordingly increases in $\theta$.

Consequently, the entrant's profit $\pi_{e}(\theta)$ is concave in $\theta$. Since the entrant makes a higher profit when he is unbiased $(\theta=1)$ versus biased, the entrant's profit $\pi_{e}(\theta)$ decreases (increases) in $\theta$ when $\theta>1(\theta<1)$.

(b)From (7), the incumbent's profit $\pi_{i}(\theta)$ is affected by $\theta$ via $x_{e}(\theta)$, which increases in $\theta$ from part (a). Moreover, the incumbent's profit increases in the entrant's position $x_{e}(\theta)$ (Lemma 1b). As a result, the incumbent's profit $\pi_{i}(\theta)$ increases in $\theta$.

Proof of Corollary 6 When $\theta>1, \pi_{i}(\theta)$ increases in $\theta$ (Lemma 4b) while $\pi_{e}(\theta)$ decreases in $\theta$ (Lemma 4a). Thus, $\Delta(\theta)=\pi_{i}(\theta)-\pi_{e}(\theta)$ increases in $\theta-1$ when $\theta>1$. When $\theta<1$,

$$
\begin{aligned}
\left.\Delta \prime(\theta)\right|_{\theta=1} & =\left.\pi_{i}(\theta)\right|_{\theta=1}-\left.\pi_{e} \prime(\theta)\right|_{\theta=1} \\
& =\left.\frac{d \pi_{i}(\theta)}{d x_{e}(\theta)} \frac{d x_{e}(\theta)}{d \theta}\right|_{\theta=1}-\left.\frac{d \pi_{e}(\theta)}{d x_{e}(\theta)} \frac{d x_{e}(\theta)}{d \theta}\right|_{\theta=1} \\
& =\left.\frac{\left[3+x_{i}(\theta)+x_{e}(\theta)\right]\left[3+3 x_{e}(\theta)-x_{i}(\theta)\right]}{18} \frac{d x_{e}(\theta)}{d \theta}\right|_{\theta=1}>0,
\end{aligned}
$$

where the second equality follows from $\left.\frac{d \pi_{e}(\theta)}{d x_{e}(\theta)}\right|_{\theta=1}=0$ (the envelope theorem). Thus, $\Delta(\theta)$ decreases in $1-\theta$ around $\theta=1$.

Follower advantage without repositioning costs. Let $x_{i}^{a}$ represent the incumbent's position after repositioning. Given $x_{i}^{a}$ and $x_{e}(\theta)$, from (6) to (7), the entrant's profit is $\pi_{e}=\frac{\left[x_{e}(\theta)-x_{i}^{a}\right]\left[3-x_{i}^{a}-x_{e}(\theta)\right]^{2}}{18}$ while the entrant's profit is $\pi_{i}=\frac{\left[x_{e}(\theta)-x_{i}^{a}\right]\left[3+x_{i}^{a}+x_{e}(\theta)\right]^{2}}{18}$ if firms engage in a price competition again. As a result, $\pi_{e}-\pi_{i}=\frac{2\left[\left(x_{i}^{a}\right)^{2}-\left(x_{e}(\theta)\right)^{2}\right)}{3}>0 \Leftrightarrow\left|x_{i}^{a}\right|>\left|x_{e}(\theta)\right|$. 
Proof of Proposition 7 (a) The entrant's profit defined in (7) solves the optimization problem and consequently is higher than the profit defined in (11). That is, $\pi_{i}(\theta) \geq \pi_{i}(\theta, \theta)$ for any $\theta$. We next compare the relative performances $\Delta(\theta, \theta)$ and $\Delta(\theta)$ :

$$
\begin{aligned}
& \left.\frac{\partial \Delta(\theta, \theta)}{\partial \theta}\right|_{\theta=\theta}-\left.\frac{d \Delta(\theta)}{d \theta}\right|_{\theta=\theta}=\left.\frac{\partial \pi_{i}(\theta, \theta)}{\partial \theta}\right|_{\theta=\theta}-\left.\frac{\partial \pi_{e}(\theta, \theta)}{\partial \theta}\right|_{\theta=\theta} \\
& =-\left.\frac{\partial \pi_{e}(\theta, \theta)}{\partial \theta}\right|_{\theta=\theta} \\
& =-\left.\frac{\partial \pi_{e}(\theta, \theta)}{\partial x_{i}(\theta)} \frac{d x_{i}(\theta)}{d \theta}\right|_{\theta=\theta} \\
& =\left.\frac{\left[3+x_{e}(\theta)-3 x_{i}(\theta)\right]\left[3-x_{i}(\theta)-x_{e}(\theta)\right]}{18} \frac{d x_{i}(\theta)}{d \theta}\right|_{\theta=\theta} \\
& =\left.\frac{\left[3+x_{e}(\theta)-3 x_{i}(\theta)\right]\left[3-x_{i}(\theta)-x_{e}(\theta)\right]}{18} \frac{d x_{i}^{k}\left(x_{e}(\theta)\right)}{d x_{e}(\theta)} \frac{x_{e}(\theta)}{d \theta}\right|_{\theta=\theta} \\
& >0
\end{aligned}
$$

where the second equality is from the envelope theorem, the third and fourth equalities are from (10), the last equality is from (5), and the inequality is from $\frac{d x_{i}^{k}\left(x_{e}(\theta)\right)}{d x_{e}(\theta)}>0$ (Lemma 1b) and $\frac{x_{e}(\theta)}{d \theta}>0$ (the proof of Lemma 4a). We therefore conclude because $\Delta(\theta, \theta=\theta)=\Delta(\theta)$.

(b)From (10),

$$
\begin{aligned}
\frac{\partial \pi_{e}(\theta, \theta)}{\partial \theta} & =\frac{\partial \pi_{e}(\theta, \theta)}{\partial x_{i}(\theta)} \frac{d x_{i}(\theta)}{d \theta} \\
& =-\frac{\left[3+x_{e}(\theta)-3 x_{i}(\theta)\right]\left[3-x_{i}(\theta)-x_{e}(\theta)\right]}{18} \frac{d x_{i}(\theta)}{d \theta} \\
& =-\frac{\left[3+x_{e}(\theta)-3 x_{i}(\theta)\right]\left[3-x_{i}(\theta)-x_{e}(\theta)\right]}{18} \frac{d x_{i}^{k}\left(x_{e}(\theta)\right)}{d x_{e}(\theta)} \frac{x_{e}(\theta)}{d \theta} \\
& <0,
\end{aligned}
$$

where the inequality is from $\frac{d x_{i}^{k}\left(x_{e}(\theta)\right)}{d x_{e}(\theta)}>0$ (Lemma 1b) and $\frac{x_{e}(\theta)}{d \theta}>0$ (the proof of Lemma 4a). We can therefore conclude because $\pi_{e}(\theta, \theta)=\pi_{e}(\theta)$ when $\theta=\theta$.

Proof of Proposition 8 First, entrant bias hurts the entrant because $\pi_{e}(\theta) \leq \pi_{e}^{k}$ from (8) and (6). Moreover, incumbent bias hurts the incumbent $\pi_{i}(\theta, \theta) \leq \pi_{i}(\theta)$ from Proposition 1. Second, we show that biased firms can earn more profit than unbiased firms. It is sufficient to consider $k=0$. From (10) and (11), we find that $\pi_{e}(\theta, \theta)=\frac{\left[x_{e}(\theta)-x_{i}(\theta)\right]\left[3-x_{i}(\theta)-x_{e}(\theta)\right]^{2}}{18}>\pi_{e}^{k}=\frac{8}{9}$ and $\pi_{i}(\theta, \theta)=$ $\frac{\left[x_{e}(\theta)-x_{i}(\theta)\right]\left[3+x_{i}(\theta)+x_{e}(\theta)\right]^{2}}{18}>\pi_{i}^{k}=\frac{2}{9}$ hold when $x_{i}(\theta)$ is relatively low and $x_{e}(\theta)$ is relatively high, that is, when $\theta>1$ and $\theta<\theta$. As a result, there exists $\bar{k}$ such that, if $k<\bar{k},\left(\pi_{e}(\theta, \theta), \pi_{i}(\theta, \theta)\right)>\left(\pi_{e}^{k}, \pi_{i}^{k}\right)$ when $\theta>1$ and $\theta<\theta$. 
Proof of Proposition 9 (a) The incumbent who is aware of entrant bias has the equilibrium profit in (7) $\pi_{i}(\theta)=\max _{x_{i}} \frac{\left[x_{e}(\theta)-x_{i}\right]\left[3+x_{i}+x_{e}(\theta)\right]^{2}}{18}-k\left|x_{i}\right| \geq \frac{\left[x_{e}(\theta)-x_{i}^{k}\right]\left[3+x_{i}^{k}+x_{e}(\theta)\right]^{2}}{18}-k\left|x_{i}^{k}\right|=\tilde{\pi}_{i}(\theta)$. That is, the unawareness of incumbent leads to a lower profit for the incumbent.

For the relative profit, consider $\theta=1-\epsilon$, where $\epsilon>0$ is significantly small. As the incumbent becomes unaware of entrant bias, the incumbent's position changes (increases). However, the incumbent's loss from unawareness is significantly small (zero from the envelope theorem) because $\epsilon$ is significantly small and $\theta \approx 1$. However, the entrant's loss from the incumbent's position is comparatively large. Moreover, the entrant's loss dominants the incumbent's loss and incumbent unawareness helps her relative performance.

(b)When $\theta<1$, the incumbent unawareness leads to an increasing incumbent position, which hurts the entrant.

Proof of Proposition 10 First, entrant bias hurts the entrant because $\pi_{e}(\theta) \leq \pi_{e}^{k}$ from (8) and (6). Moreover, incumbent bias hurts the incumbent $\tilde{\pi}_{i}(\theta) \leq \pi_{i}(\theta)$ from part (a) in this proof. Second, we show that biased firm can earn more profit than unbiased firms. It is sufficient to consider $k=0$. From (12) and (13), $\tilde{\pi}_{e}(\theta)=\frac{\left[x_{e}(\theta)-x_{i}^{k}\right]\left[3-x_{i}^{k}-x_{e}(\theta)\right]^{2}}{18}>\pi_{e}^{k}=\frac{8}{9}$ and $\tilde{\pi}_{i}(\theta)=\frac{\left[x_{e}(\theta)-x_{i}^{k}\right]\left[3+x_{i}^{k}+x_{e}(\theta)\right]^{2}}{18}>\pi_{i}^{k}=\frac{2}{9}$ hold when $x_{i}^{k}$ is relatively low and $x_{e}(\theta)$ is relatively high. Thus, we can conclude that, if $\theta>1$ and $k<\bar{k}$, where $\bar{k}$ is defined in Proposition 2, then $\left(\tilde{\pi}_{e}(\theta), \tilde{\pi}_{i}(\theta)\right)>\left(\pi_{e}^{k}, \pi_{i}^{k}\right)$.

Proof of Proposition 11 Since $\frac{\partial \pi_{e}(\theta, \theta)}{\partial \theta}<0$ (the proof of Proposition 1b), $\tilde{\pi}_{e}(\theta)=\pi_{e}(\theta, \theta=1)>\pi_{e}(\theta, \theta)$ when $\theta<1$. The objective function of (11) shows that the entrant's profit is concave in $x_{i}(\theta)$ for any $x_{e}(\theta)$ from the proof of Lemma 1. For any entrant position $x_{e}(\theta)$, we define $x_{i}^{*}(\theta)=\arg \max _{x_{i}} \frac{\left[x_{e}(\theta)-x_{i}\right]\left[3+x_{i}+x_{e}(\theta)\right]^{2}}{18}-k\left|x_{i}\right|$. When $\theta>1, x_{e}(\theta)>x_{e}(1)=x_{e}^{k}$ because $x_{e}(\theta)$ increases in $\theta$ from the proof of Lemma 5. Thus, $x_{i}^{*}(\theta)=x_{i}^{k}\left(x_{e}(\theta)\right)>x_{i}^{k}\left(x_{e}^{k}\right)=x_{i}^{k}$ because $x_{i}^{k}\left(x_{e}\right)$ increases in $x_{e}$ (Lemma 1) and $x_{e}(\theta)>x_{e}^{k}$. Furthermore, $x_{i}^{k}=x_{i}(\theta=1)>x_{i}(\theta)$ when $\theta<1$ because $x_{i}(\theta)$ increases in $\theta$ from the proof of Proposition $1 \mathrm{~b}$. When $\theta>1>\theta, x_{i}^{*}(\theta)>x_{i}^{k}>x_{i}(\theta)$, and consequently $\tilde{\pi}_{i}(\theta)>\pi_{i}(\theta, \theta)$ from (11) and (13). 